ISSN: 2641-9475

\title{
The Importance of Attenuated Total Reflectance Fourier Transform Infrared (ATR-FTIR) and Raman Biospectroscopy of Single-Walled Carbon Nanotubes (SWCNT) and Multi- Walled Carbon Nanotubes (MWCNT) in Interpreting Infrared and Raman Spectra of Human Cancer Cells, Tissues and Tu-
} mors

\author{
Alireza Heidari*1,2, Jennifer Esposito ${ }^{1}$, Angela Caissutti ${ }^{1}$ \\ ${ }^{1}$ Faculty of Chemistry, California South University, 14731 Comet St. Irvine, CA 92604, USA \\ ${ }^{2}$ American International Standards Institute, Irvine, CA 3800, USA
}

\section{${ }^{*}$ Corresponding author:}

\section{Alireza Heidari}

American International Standards Institute,

Irvine, CA 3800, USA

Received : January 31, 2019

Published : March 12, 2019

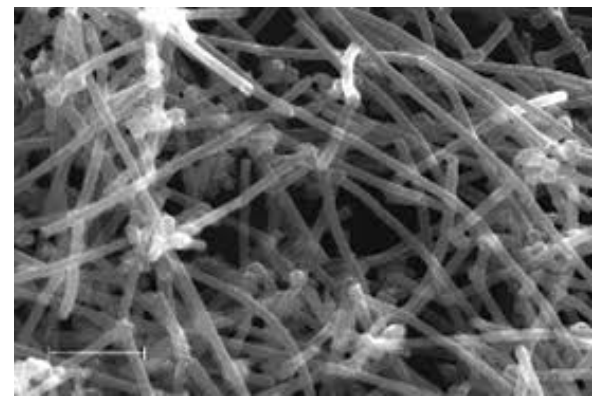

Scanning Electron Microscope (SEM) image of Single-Walled Carbon Nanotubes (SWCNT) with 90000x zoom.

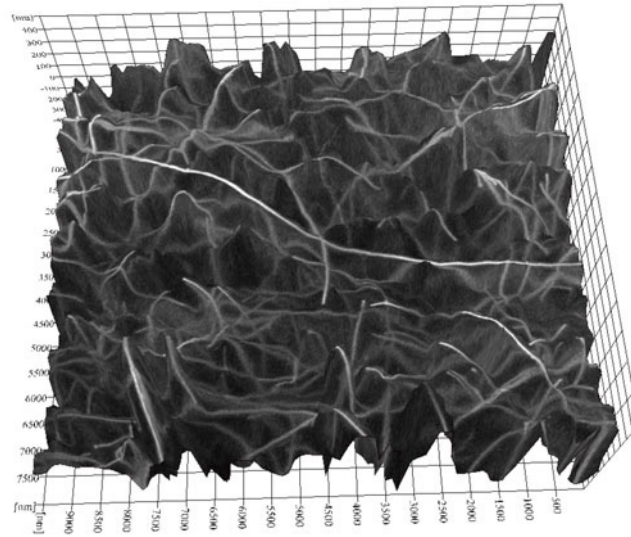

\section{Graphical Abstract}

In the current research, structure of Single-Walled Carbon Nanotubes (SWCNT) and Multi-Walled Carbon Nanotubes (MWCNT) was investigated by Attenuated Total Reflectance Fourier Transform Infrared (ATR-FTIR) and Raman spectroscopies and it was combined with Carbon nanotubes to evaluate its ability in act as radar absorber for interpreting infrared and Raman spectra of human cancer cells, tissues and tumors. In order to structurally characterize the sample and to determine characteristics related to degree of wave absorption by the sample, some analyses such as Back Scattering Raman, Attenuated Total Reflectance Fourier Transform Infrared Biospectroscopy (ATR-FTIR), X-Ray Diffraction (XRD) and Network Analyzer (NA) were used. The structure of Single-Walled Carbon Nanotubes (SWCNT) and Multi-Walled Carbon Nanotubes (MWCNT) was clearly observable through active modes of Raman spectra and results of X-Ray Diffraction (XRD). According to Network Analyzer (NA) spectrum analysis, the effect of nanotubes on wave absorption characteristics of sample was determined for interpreting infrared and Raman spectra of human cancer cells, tissues and tumors.

Keywords: Single-Walled Carbon Nanotubes (SWCNT), MultiWalled Carbon Nanotubes (MWCNT), X-Ray Diffraction (XRD), Back Scattering Raman, Attenuated Total Reflectance Fourier Transform Infrared Biospectroscopy (ATR-FTIR), Raman Biospectroscopy, Network Analyzer (NA), Scanning Electron Microscope (SEM), Interpreting, Infrared Spectra, Raman Spectra, Human Cancer Cells, Tissues and Tumors

3D simulation of Multi-Walled Carbon Nanotubes (MWCNT).

Citation: Heidari A (2019). The Importance of Attenuated Total Reflectance Fourier Transform Infrared (ATR-FTIR) and Raman Biospectroscopy of Single-Walled Carbon Nanotubes (SWCNT) and Multi-Walled Carbon Nanotubes (MWCNT) in Interpreting Infrared and Raman Spectra of Human Cancer Cells, Tissues and Tumors. Oncogen 2(2): 7. 


\section{Introduction}

Single-Walled Carbon Nanotubes (SWCNT) and Multi-Walled Carbon Nanotubes (MWCNT) are magnetics that are very useful due to their various applications and high electromagnetic efficiency in a wide range of frequency [1-12]. In recent years, due to extraordinary use of electronic tools such as cellphone, private computers and radar systems, interference of electromagnetic waves and its harmful effects have been widely interested. As a result, investigation about electromagnetic wave absorbers are increasingly developed [12-15].

Among wave absorbers, soft magnetic Single-Walled Carbon Nanotubes (SWCNT) and Multi-Walled Carbon Nanotubes (MWCNT) can be an appropriate option in investigation about wave absorbers because of having characteristics such as high magnetic saturation, considerable Snoek's limit, high magnetic coercivity, high chemical stability and resistance against corrosion $[16,17]$.

Regarding the fact that Raman spectra can be considered as finger print of each chemicals, the aim of the current study is to structurally investigate one of these chemicals called SingleWalled Carbon Nanotubes (SWCNT) and Multi-Walled Carbon Nanotubes (MWCNT). Moreover, due to special physicchemical characteristics of Single-Walled Carbon Nanotubes (SWCNT) and Multi-Walled Carbon Nanotubes (MWCNT) such as low weight, resistance against corrosion, high mechanical strength, high flexibility and unique electrical performance [18-223], the effect of these nanotubes on radar absorption ability of Single-Walled Carbon Nanotubes (SWCNT) and Multi-Walled Carbon Nanotubes (MWCNT) was studied by analyzing network analyzer (NA) spectrum for interpreting infrared and Raman spectra of human cancer cells, tissues and tumors such as Carcinomas, Sarcomas, Myelomas, Leukemias, Lymphomas, Mixed types (including blastomas), Adenocarcinomas: Adenocarcinomas begin in glandular cells that manufacture fluids, such as breast milk, Squamous cell carcinomas: Examples of squamous cells include those in the top layer of the skin, the upper portion of the esophagus and airways, and the lower portion of the cervix and vagina, Basal cell carcinomas: Basal cells are only present in the skin and are the deepest layer of skin cells, Transitional cell carcinomas: Transitional cells are epithelial cells that are "stretchy" and are present in the bladder and parts of the kidney, Osteosarcoma (bone cancers): Osteocytes are bone cells, Chondrosarcoma (cartilage cancers): Cartilage cells are called chondroblasts, Liposarcoma (fatty tissue cancers), Rhabdomyosarcoma (skeletal muscle cancers), Leiomyosarcoma (smooth muscle cancers), Angiosarcoma (blood vessel cancers), Mesothelioma (cancers of the mesothelium, the tissues that line the chest and abdominal cavities), Fibrosarcoma (cancers of fibrous tissues), Glioma and astrocytoma (cells of the connective tissue in the brain), Acute lymphocytic leukemias (ALL): These are cancers of white blood cells known as lymphocytes, Chronic lymphocytic leukemia (CLL), Acute myelocytic leukemias (AML): These are cancers of mature or immature cells known as myelocytes, such as neutrophils, Chronic myelocytic leukemia (CML), Hodgkin lymphoma, Non-Hodgkin lymphoma, Oral cancer: Roughly 85 percent of head and neck cancers are oral cancers. These cancers may involve the mouth, the tongue, the tonsils, the throat (the pharynx), and the nasal passageways, Laryngeal cancer: (cancer of the vocal cords), Ductal carcinoma in situ of the breast and lobular carcinoma in situ, Invasive (infiltrating) breast cancer (both ductal and lobular), Inflammatory breast cancer, Male breast cancer, Non-small cell lung cancer, Small cell lung cancer, Mesothelioma, Esophageal cancer, Stomach cancer, Pancreatic cancer, Liver cancer, Colon cancer, Anal cancer, Kidney cancer, Bladder cancer, Prostate cancer, Testicular cancer, Ovarian cancer (including germ cell tumors), Uterine cancer (endometrial cancer), Fallopian tube cancer, Cervical cancer, Thyroid cancer, Osteosarcoma (bone cancers), Kaposi's sarcoma: Kaposi's sarcoma is a soft tissue cancer often seen in people with HIV/AIDS, Ewing's sarcoma: Ewing's sarcoma is a bone cancer that primarily affects children, Hodgkin's lymphoma, Non-Hodgkin's lymphoma, Acute lymphocytic leukemia $(A L L)$, Chronic lymphocytic leukemia (CLL), Acute myelogenous leukemia (AML), Chronic myelogenous leukemia (CML), Myeloma, Melanoma, Squamous cell carcinoma of the skin, Basal cell carcinoma, By the grade of the tumor, By the stage of the tumor, Non-hereditary cancer vs hereditary cancer, DNA/ RNA molecular profiles.

\section{Methodology}

An analogy to describe cancer cells has been that of a car. The growth of the cells can be pictured as a car that has the accelerator stuck down. At the same time, the brakes don't work (the cells doesn't respond to tumor suppressor proteins.)

We can take this analogy a step further. The invasion of cancer cells can be viewed as a car breaking through a gate into a gated community. Normal cells respond to signals from neighboring cells that say "this is my boundary, stay out." Cancer cells are antisocial in other ways as well. As they "gang" up with other cancer cells, all of which are becoming more immature 
in their actions over time (due to rapid division), they spread out and invade other communities as well.

But just as crime hasn't overridden the United States, there are many police officers (checkpoints) that keep the majority of cells in the body in line.

It is actually very difficult for a normal cell to become a cancer cell. It has to be abnormal in ways that facilitate growth, inhibit repair and death, ignore signals from neighbors, and achieve a form of immortality. This is why cancer isn't caused by a single mutation, but rather by a series of mutations. But considering that a billion cells in our bodies divide every day, something is bound to go wrong and mutations occur once in a while. And they do, for an estimated 1.6 million people in the United States each year.

\section{Results and Discussion}

As we know, each crystalline structure has different labels for its Raman active modes in Raman spectrum and this unique combination of modes is the characteristic of each structure and called as finger print of structure. In this regard, to investigate the formation of Single-Walled Carbon Nanotubes (SWCNT) and Multi-Walled Carbon Nanotubes (MWCNT) structure and to identify its modes, Raman dispersion spectrum of both produced samples at two different temperatures are shown in Figure (1).
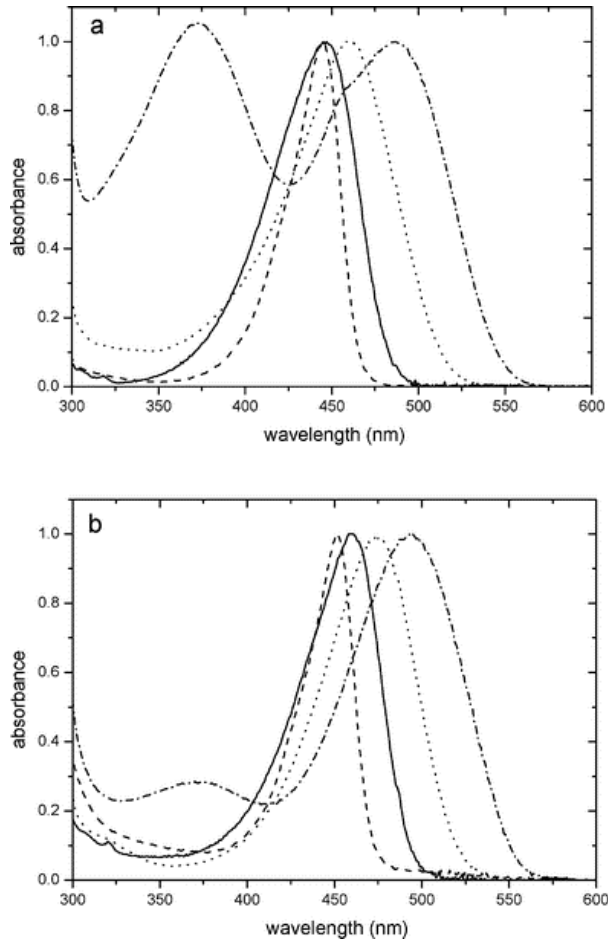

Figure 1: Raman dispersion spectrum of (a) Single-Walled Carbon Nanotubes (SWCNT), (b) Multi-Walled Carbon Nanotubes (MWCNT)
As spinel oxides of metallic conductors are divided into normal and reverse groups, Single-Walled Carbon Nanotubes (SWCNT) and Multi-Walled Carbon Nanotubes (MWCNT) have a reverse spinel structure and its initial symmetry and spatial group are $O_{h}^{7}$ and $F D \overline{3} m$, respectively.

The difference between these two spectrums is that the related modes are of lower intensity in lower temperature and at the other hand, additional modes are observed that can be attributed to incomplete structure and presence of impurities such as Single-Walled Carbon Nanotubes (SWCNT) and MultiWalled Carbon Nanotubes (MWCNT). Adjacent to each of these modes, observing a small peak (like a brush) is possible which attributed of reverse spinel structure of Single-Walled Carbon Nanotubes (SWCNT) and Multi-Walled Carbon Nanotubes (MWCNT) that emerge as $\mathrm{E}_{\mathrm{g}}$ and $\mathrm{A}_{1 \mathrm{~g}}$ modes.

To investigate functional groups presented in the compound, Attenuated Total Reflectance Fourier Transform Infrared (ATRFTIR) analysis was used for interpreting infrared and Raman spectra of human cancer cells, tissues and tumors such as Carcinomas, Sarcomas, Myelomas, Leukemias, Lymphomas, Mixed types (including blastomas), Adenocarcinomas: Adenocarcinomas begin in glandular cells that manufacture fluids, such as breast milk, Squamous cell carcinomas: Examples of squamous cells include those in the top layer of the skin, the upper portion of the esophagus and airways, and the lower portion of the cervix and vagina, Basal cell carcinomas: Basal cells are only present in the skin and are the deepest layer of skin cells, Transitional cell carcinomas: Transitional cells are epithelial cells that are "stretchy" and are present in the bladder and parts of the kidney, Osteosarcoma (bone cancers): Osteocytes are bone cells, Chondrosarcoma (cartilage cancers): Cartilage cells are called chondroblasts, Liposarcoma (fatty tissue cancers), Rhabdomyosarcoma (skeletal muscle cancers), Leiomyosarcoma (smooth muscle cancers), Angiosarcoma (blood vessel cancers), Mesothelioma (cancers of the mesothelium, the tissues that line the chest and abdominal cavities), Fibrosarcoma (cancers of fibrous tissues), Glioma and astrocytoma (cells of the connective tissue in the brain), Acute lymphocytic leukemias (ALL): These are cancers of white blood cells known as lymphocytes, Chronic lymphocytic leukemia (CLL), Acute myelocytic leukemias (AML): These are cancers of mature or immature cells known as myelocytes, such as neutrophils, Chronic myelocytic leukemia (CML), Hodgkin lymphoma, Non-Hodgkin lymphoma, Oral cancer: Roughly 85 percent of head and neck cancers are oral cancers. These cancers may involve the mouth, the tongue, the tonsils, the

Citation: Heidari A (2019). The Importance of Attenuated Total Reflectance Fourier Transform Infrared (ATR-FTIR) and Raman Biospectroscopy of Single-Walled Carbon Nanotubes (SWCNT) and Multi-Walled Carbon Nanotubes (MWCNT) in Interpreting Infrared and Raman Spectra of Human Cancer Cells, Tissues and Tumors. Oncogen 2(2): 7. 
throat (the pharynx), and the nasal passageways, Laryngeal cancer: (cancer of the vocal cords), Ductal carcinoma in situ of the breast and lobular carcinoma in situ, Invasive (infiltrating) breast cancer (both ductal and lobular), Inflammatory breast cancer, Male breast cancer, Non-small cell lung cancer, Small cell lung cancer, Mesothelioma, Esophageal cancer, Stomach cancer, Pancreatic cancer, Liver cancer, Colon cancer, Anal cancer, Kidney cancer, Bladder cancer, Prostate cancer, Testicular cancer, Ovarian cancer (including germ cell tumors), Uterine cancer (endometrial cancer), Fallopian tube cancer, Cervical cancer, Thyroid cancer, Osteosarcoma (bone cancers), Kaposi's sarcoma: Kaposi's sarcoma is a soft tissue cancer often seen in people with HIV/AIDS, Ewing's sarcoma: Ewing's sarcoma is a bone cancer that primarily affects children, Hodgkin's lymphoma, Non-Hodgkin's lymphoma, Acute lymphocytic leukemia $(A L L)$, Chronic lymphocytic leukemia (CLL), Acute myelogenous leukemia (AML), Chronic myelogenous leukemia (CML), Myeloma, Melanoma, Squamous cell carcinoma of the skin, Basal cell carcinoma, By the grade of the tumor, By the stage of the tumor, Non-hereditary cancer vs hereditary cancer, DNA/ RNA molecular profiles. Each compound or bond vibrates in its characteristic wave number due to the emitted force. This phenomenon emerges in the spectrum as absorption. In this regard, Figure (2) shows Attenuated Total Reflectance Fourier Transform Infrared (ATR-FTIR) spectrum of Single-Walled Carbon Nanotubes (SWCNT) and Multi-Walled Carbon Nanotubes (MWCNT).

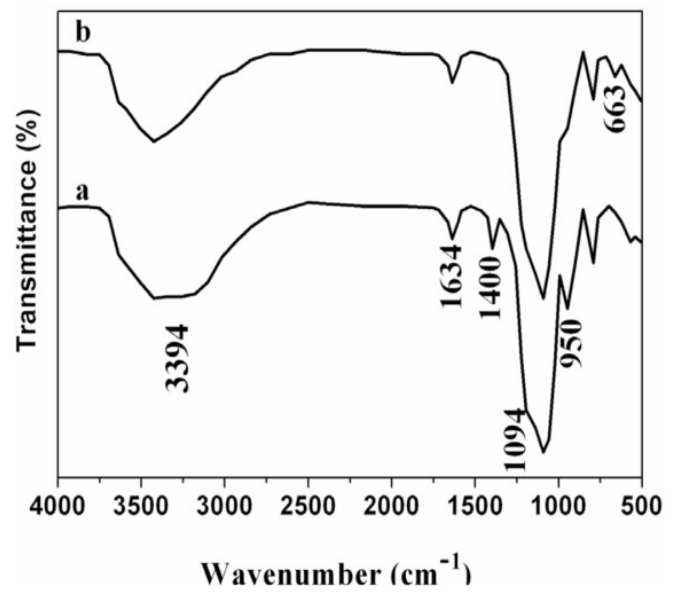

Figure 2: Attenuated Total Reflectance Fourier Transform Infrared (ATR-FTIR) spectrum of (a) Single-Walled Carbon Nanotubes (SWCNT), (b) Multi-Walled Carbon Nanotubes (MWCNT).

There are four active IR for this structure that are emerged in $v_{1}$ $\left(613-890 \mathrm{~cm}^{-1}\right), v_{2}\left(1044-1390 \mathrm{~cm}^{-1}\right), v_{3}\left(1400-1590 \mathrm{~cm}^{-1}\right)$ and $\mathrm{v}_{4}\left(1590-3420 \mathrm{~cm}^{-1}\right)$. Two bands are in far-infrared zone (FarIR) and are not observable. Comparing two spectrums show that characteristic modes are of higher intensity and there are not additional modes. This can be attributed to complete formation of crystalline structure of Single-Walled Carbon Nanotubes (SWCNT) and Multi-Walled Carbon Nanotubes (MWCNT).

The spectrum of network analyzer (NA) which is shown in Figure (3) indicates the amount of wave absorption in frequency range of $14-44(\mathrm{GHz})$ related to Single-Walled Carbon Nanotubes (SWCNT) and Multi-Walled Carbon Nanotubes (MWCNT) samples. According to comparison with the single samples of Single-Walled Carbon Nanotubes (SWCNT) and Multi-Walled Carbon Nanotubes (MWCNT), a considerable change was observed in the amount of compound absorption in relation with single sample and it can be concluded that the considered compound is of important and favorable abilities for applying as radar absorption covers for interpreting infrared and Raman spectra of human cancer cells, tissues and tumors such as Carcinomas, Sarcomas, Myelomas, Leukemias, Lymphomas, Mixed types (including blastomas), Adenocarcinomas: Adenocarcinomas begin in glandular cells that manufacture fluids, such as breast milk, Squamous cell carcinomas: Examples of squamous cells include those in the top layer of the skin, the upper portion of the esophagus and airways, and the lower portion of the cervix and vagina, Basal cell carcinomas: Basal cells are only present in the skin and are the deepest layer of skin cells, Transitional cell carcinomas: Transitional cells are epithelial cells that are "stretchy" and are present in the bladder and parts of the kidney, Osteosarcoma (bone cancers): Osteocytes are bone cells, Chondrosarcoma (cartilage cancers): Cartilage cells are called chondroblasts, Liposarcoma (fatty tissue cancers), Rhabdomyosarcoma (skeletal muscle cancers), Leiomyosarcoma (smooth muscle cancers), Angiosarcoma (blood vessel cancers), Mesothelioma (cancers of the mesothelium, the tissues that line the chest and abdominal cavities), Fibrosarcoma (cancers of fibrous tissues), Glioma and astrocytoma (cells of the connective tissue in the brain), Acute lymphocytic leukemias (ALL): These are cancers of white blood cells known as lymphocytes, Chronic lymphocytic leukemia (CLL), Acute myelocytic leukemias (AML): These are cancers of mature or immature cells known as myelocytes, such as neutrophils, Chronic myelocytic leukemia (CML), Hodgkin lymphoma, Non-Hodgkin lymphoma, Oral cancer: Roughly 85 percent of head and neck cancers are oral cancers. These cancers may involve the mouth, the tongue, the tonsils, the throat (the pharynx), and the nasal passageways, Laryngeal cancer: (cancer of the vocal cords), Ductal carcinoma in situ of 
the breast and lobular carcinoma in situ, Invasive (infiltrating) breast cancer (both ductal and lobular), Inflammatory breast cancer, Male breast cancer, Non-small cell lung cancer, Small cell lung cancer, Mesothelioma, Esophageal cancer, Stomach cancer, Pancreatic cancer, Liver cancer, Colon cancer, Anal cancer, Kidney cancer, Bladder cancer, Prostate cancer, Testicular cancer, Ovarian cancer (including germ cell tumors), Uterine cancer (endometrial cancer), Fallopian tube cancer, Cervical cancer, Thyroid cancer, Osteosarcoma (bone cancers), Kaposi's sarcoma: Kaposi's sarcoma is a soft tissue cancer often seen in people with HIV/AIDS, Ewing's sarcoma: Ewing's sarcoma is a bone cancer that primarily affects children, Hodgkin's lymphoma, Non-Hodgkin's lymphoma, Acute lymphocytic leukemia (ALL), Chronic lymphocytic leukemia (CLL), Acute myelogenous leukemia (AML), Chronic myelogenous leukemia (CML), Myeloma, Melanoma, Squamous cell carcinoma of the skin, Basal cell carcinoma, By the grade of the tumor, By the stage of the tumor, Non-hereditary cancer vs hereditary cancer, DNA/ RNA molecular profiles.

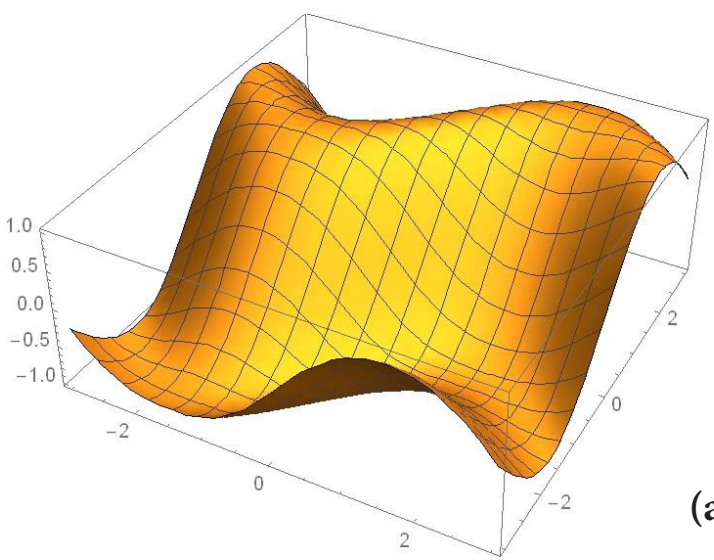

(a)

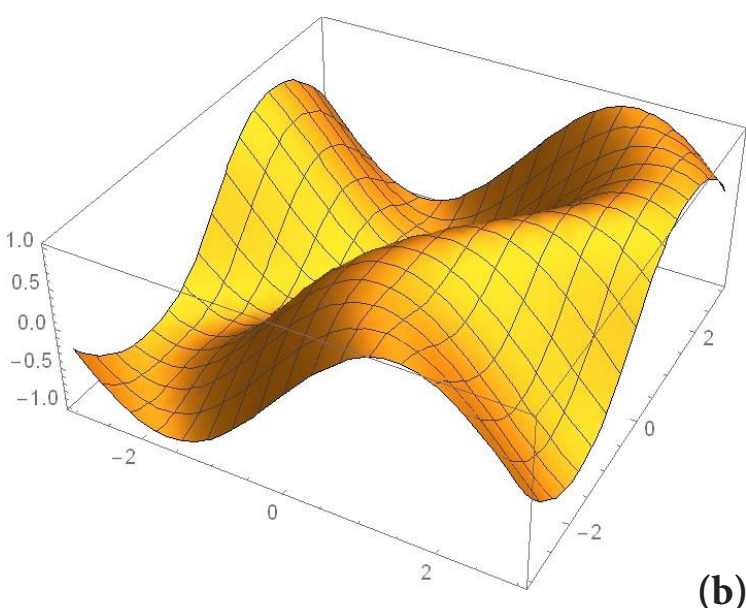

Figure 3: Dissipation of sample reflection of (a) Single-Walled Carbon Nanotubes (SWCNT), (b) Multi-Walled Carbon Nanotubes (MWCNT).
Finally, in order to identify crystalline phase and formed structure, X-Ray Diffraction (XRD) pattern of Single-Walled Carbon Nanotubes (SWCNT) and Multi-Walled Carbon Nanotubes (MWCNT) is shown in Figure (4).
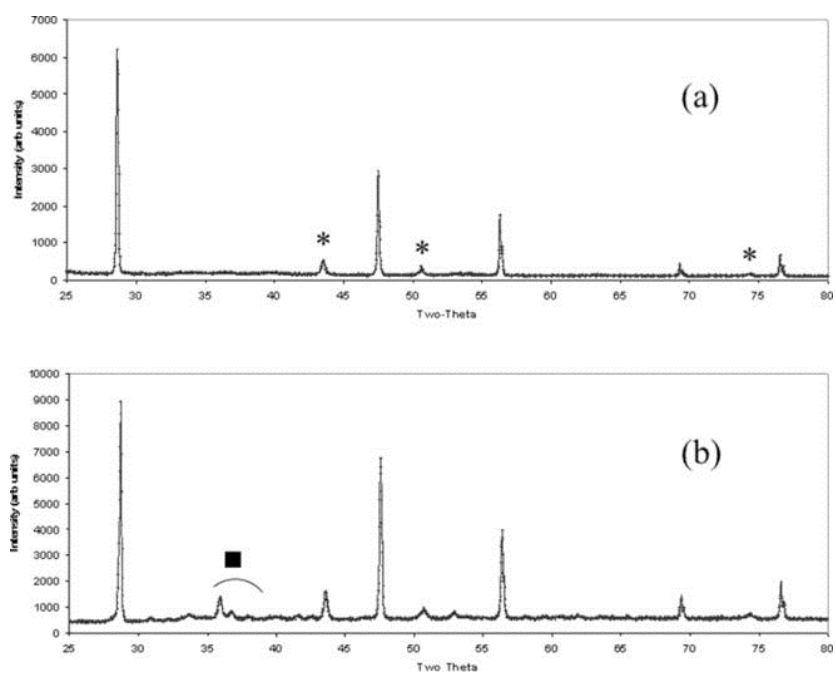

Figure 4: X-Ray Diffraction (XRD) pattern of (a) Single-Walled Carbon Nanotubes (SWCNT), (b) Multi-Walled Carbon Nanotubes (MWCNT).

This pattern is in accordance with X-Ray Diffraction (XRD) pattern of crystalline structure of Single-Walled Carbon Nanotubes (SWCNT) and Multi-Walled Carbon Nanotubes (MWCNT) and the crystalline lattice structure is face centered cubic (fcc) and the mean crystalline size is smaller than 100 (nm).

\section{Conclusion and Summary}

In the current research, in order to determine the structure of sample and characterize the vibration modes related to the sample, back scattering Raman biospectroscopy and Attenuated Total Reflectance Fourier Transform Infrared biospectroscopy (ATR-FTIR) were performed and the related modes of sample were completely identified in these spectra. Regarding the importance of electromagnetic wave absorbers in various industries, reflection dissipation spectrum of sample and effect of nanotubes on Single-Walled Carbon Nanotubes (SWCNT) and Multi-Walled Carbon Nanotubes (MWCNT) were investigated. It was observed that the presence of nanotubes is of considerable effect on wave absorption of Single-Walled Carbon Nanotubes (SWCNT) and MultiWalled Carbon Nanotubes (MWCNT) and the saved spectrum data confirm this claim for interpreting infrared and Raman spectra of human cancer cells, tissues and tumors such as Carcinomas, Sarcomas, Myelomas, Leukemias, Lymphomas, Mixed types (including blastomas), Adenocarcinomas: Adenocarcinomas begin in glandular cells that manufacture fluids,

Citation: Heidari A (2019). The Importance of Attenuated Total Reflectance Fourier Transform Infrared (ATR-FTIR) and Raman Biospectroscopy of Single-Walled Carbon Nanotubes (SWCNT) and Multi-Walled Carbon Nanotubes (MWCNT) in Interpreting Infrared and Raman Spectra of Human Cancer Cells, Tissues and Tumors. Oncogen 2(2): 7. 
such as breast milk, Squamous cell carcinomas: Examples of squamous cells include those in the top layer of the skin, the upper portion of the esophagus and airways, and the lower portion of the cervix and vagina, Basal cell carcinomas: Basal cells are only present in the skin and are the deepest layer of skin cells, Transitional cell carcinomas: Transitional cells are epithelial cells that are "stretchy" and are present in the bladder and parts of the kidney, Osteosarcoma (bone cancers): Osteocytes are bone cells, Chondrosarcoma (cartilage cancers): Cartilage cells are called chondroblasts, Liposarcoma (fatty tissue cancers), Rhabdomyosarcoma (skeletal muscle cancers), Leiomyosarcoma (smooth muscle cancers), Angiosarcoma (blood vessel cancers), Mesothelioma (cancers of the mesothelium, the tissues that line the chest and abdominal cavities), Fibrosarcoma (cancers of fibrous tissues), Glioma and astrocytoma (cells of the connective tissue in the brain), Acute lymphocytic leukemias (ALL): These are cancers of white blood cells known as lymphocytes, Chronic lymphocytic leukemia (CLL), Acute myelocytic leukemias (AML): These are cancers of mature or immature cells known as myelocytes, such as neutrophils, Chronic myelocytic leukemia (CML), Hodgkin lymphoma, Non-Hodgkin lymphoma, Oral cancer: Roughly 85 percent of head and neck cancers are oral cancers. These cancers may involve the mouth, the tongue, the tonsils, the throat (the pharynx), and the nasal passageways, Laryngeal cancer: (cancer of the vocal cords), Ductal carcinoma in situ of the breast and lobular carcinoma in situ, Invasive (infiltrating) breast cancer (both ductal and lobular), Inflammatory breast cancer, Male breast cancer, Non-small cell lung cancer, Small cell lung cancer, Mesothelioma, Esophageal cancer, Stomach cancer, Pancreatic cancer, Liver cancer, Colon cancer, Anal cancer, Kidney cancer, Bladder cancer, Prostate cancer, Testicular cancer, Ovarian cancer (including germ cell tumors), Uterine cancer (endometrial cancer), Fallopian tube cancer, Cervical cancer, Thyroid cancer, Osteosarcoma (bone cancers), Kaposi's sarcoma: Kaposi's sarcoma is a soft tissue cancer often seen in people with HIV/AIDS, Ewing's sarcoma: Ewing's sarcoma is a bone cancer that primarily affects children, Hodgkin's lymphoma, Non-Hodgkin's lymphoma, Acute lymphocytic leukemia (ALL), Chronic lymphocytic leukemia (CLL), Acute myelogenous leukemia (AML), Chronic myelogenous leukemia (CML), Myeloma, Melanoma, Squamous cell carcinoma of the skin, Basal cell carcinoma, By the grade of the tumor, By the stage of the tumor, Non-hereditary cancer vs hereditary cancer, DNA/ RNA molecular profiles.

\section{Acknowledgements}

Authors are supported by an American International Standards Institute (AISI) Future Fellowship Grant FT1201009373470. We acknowledge Ms. Isabelle Villena for instrumental support and Dr. Michael N. Cocchi for constructing Scanning Electron Microscope (SEM) image of Single-Walled Carbon Nanotubes (SWCNT) with 90000x zoom. We gratefully acknowledge Prof. Dr. Christopher Brown for proof reading the manuscript.

\section{References}

1. Heidari A and Brown C (2015) Study of Composition and Morphology of Cadmium Oxide (CdO) Nanoparticles for Eliminating Cancer Cells. J Nanomed Res 2(5): 20

2. A Heidari, C Brown (2015) Study of Surface Morphological, Phytochemical and Structural Characteristics of Rhodium (III) Oxide (Rh2O3) Nanoparticles. International Journal of Pharmacology. Phytochemistry and Ethnomedicine 1(1): 15-19

3. A Heidari (2016) An Experimental Biospectroscopic Study on Seminal Plasma in Determination of Semen Quality for Evaluation of Male Infertility. Int J Adv Technol 7: e007

4. A Heidari (2016) Extraction and Preconcentration of NTolyl-Sulfonyl-Phosphoramid-Saeure-Dichlorid as an Anti-Cancer Drug from Plants: A Pharmacognosy Study. J Pharmacogn Nat Prod 2: e103

5. A Heidari (2016) A Thermodynamic Study on Hydration and Dehydration of DNA and RNA-Amphiphile Complexes. J Bioeng Biomed Sci S 006

6. A Heidari (2016) Computational Studies on Molecular Structures and Carbonyl and Ketene Groups' Effects of Singlet and Triplet Energies of Azidoketene $\mathrm{O}=\mathrm{C}=\mathrm{CH}-$ NNN and Isocyanatoketene $\mathrm{O}=\mathrm{C}=\mathrm{CH}-\mathrm{N}=\mathrm{C}=\mathrm{O}$. J Appl Computat Math 5: e142

7. A Heidari (2016) Study of Irradiations to Enhance the Induces the Dissociation of Hydrogen Bonds between Peptide Chains and Transition from Helix Structure to Random Coil Structure Using ATR-FTIR, Raman and 1HNMR Spectroscopies. J Biomol Res Ther 5: e146

8. A Heidari (2016) Future Prospects of Point Fluorescence Spectroscopy, Fluorescence Imaging and Fluorescence Endoscopy in Photodynamic Therapy (PDT) for Cancer Cells. J Bioanal Biomed 8: e135

Citation: Heidari A (2019). The Importance of Attenuated Total Reflectance Fourier Transform Infrared (ATR-FTIR) and Raman Biospectroscopy of Single-Walled Carbon Nanotubes (SWCNT) and Multi-Walled Carbon Nanotubes (MWCNT) in Interpreting Infrared and Raman Spectra of Human Cancer Cells, Tissues and Tumors. Oncogen 2(2): 7. 
9. A Heidari (2016) A Bio-Spectroscopic Study of DNA Density and Color Role as Determining Factor for Absorbed Irradiation in Cancer Cells. Adv Cancer Prev 1: e102

10. A Heidari (2016) Manufacturing Process of Solar Cells Using Cadmium Oxide (CdO) and Rhodium (III) Oxide (Rh2O3) Nanoparticles. J Biotechnol Biomater 6: e125

11. A Heidari (2016) A Novel Experimental and Computational Approach to Photobiosimulation of Telomeric DNA/ RNA: A Biospectroscopic and Photobiological Study. J Res Development 4: 144

12. A Heidari (2016) Biochemical and Pharmacodynamical Study of Microporous Molecularly Imprinted Polymer Selective for Vancomycin, Teicoplanin, Oritavancin, Telavancin and Dalbavancin Binding. Biochem Physiol 5: e146

13. A Heidari (2016) Anti-Cancer Effect of UV Irradiation at Presence of Cadmium Oxide (CdO) Nanoparticles on DNA of Cancer Cells: A Photodynamic Therapy Study, Arch Cancer Res 4: 1

14. A Heidari (2016) Biospectroscopic Study on Multi-Component Reactions (MCRs) in Two A-Type and B-Type Conformations of Nucleic Acids to Determine Ligand Binding Modes, Binding Constant and Stability of Nucleic Acids in Cadmium Oxide (CdO) Nanoparticles-Nucleic Acids Complexes as Anti-Cancer Drugs, Arch Cancer Res 4: 2

15. A Heidari (2016) Simulation of Temperature Distribution of DNA/RNA of Human Cancer Cells Using Time-Dependent Bio-Heat Equation and Nd: YAG Lasers. Arch Cancer Res 4: 2

16. A Heidari (2016) Quantitative Structure-Activity Relationship (QSAR) Approximation for Cadmium Oxide (CdO) and Rhodium (III) Oxide (Rh2O3) Nanoparticles as Anti-Cancer Drugs for the Catalytic Formation of Proviral DNA from Viral RNA Using Multiple Linear and Non-Linear Correlation Approach. Ann Clin Lab Res 4: 1

17. A Heidari (2016) Biomedical Study of Cancer Cells DNA Therapy Using Laser Irradiations at Presence of Intelligent Nanoparticles. J Biomedical Sci 5: 2

18. A Heidari (2016) Measurement the Amount of Vitamin D2 (Ergocalciferol), Vitamin D3 (Cholecalciferol) and Absorbable Calcium (Ca2+), Iron (II) (Fe2+), Magnesium (Mg2+), Phosphate (PO4-) and Zinc (Zn2+) in Apricot Using High-
Performance Liquid Chromatography (HPLC) and Spectroscopic Techniques. J Biom Biostat 7: 292

19. A Heidari (2016) Spectroscopy and Quantum Mechanics of the Helium Dimer (He2+), Neon Dimer (Ne2+), Argon Dimer (Ar2+), Krypton Dimer (Kr2+), Xenon Dimer (Xe2+), Radon Dimer(Rn2+) and Ununoctium Dimer (Uuo2+) Molecular Cations. Chem Sci J 7: e112

20. A Heidari (2016) Human Toxicity Photodynamic Therapy Studies on DNA/RNA Complexes as a Promising New Sensitizer for the Treatment of Malignant Tumors Using BioSpectroscopic Techniques. J Drug Metab Toxicol 7: e129

21. A Heidari (2016) Novel and Stable Modifications of Intelligent Cadmium Oxide (CdO) Nanoparticles as Anti-Cancer Drug in Formation of Nucleic Acids Complexes for Human Cancer Cells' Treatment. Biochem Pharmacol (Los Angel) 5: 207

22. A Heidari (2016) A Combined Computational and QM/MM Molecular Dynamics Study on Boron Nitride Nanotubes (BNNTs), Amorphous Boron Nitride Nanotubes (a-BNNTs) and Hexagonal Boron Nitride Nanotubes (h-BNNTs) as Hydrogen Storage. Struct Chem Crystallogr Commun 2: 1

23. A Heidari (2016) Pharmaceutical and Analytical Chemistry Study of Cadmium Oxide (CdO) Nanoparticles Synthesis Methods and Properties as Anti-Cancer Drug and its Effect on Human Cancer Cells. Pharm Anal Chem Open Access 2: 113

24. A Heidari (2016) A Chemotherapeutic and Biospectroscopic Investigation of the Interaction of Double-Standard DNA/RNA-Binding Molecules with Cadmium Oxide (CdO) and Rhodium (III) Oxide (Rh2O3) Nanoparticles as Anti-Cancer Drugs for Cancer Cells' Treatment. Chemo Open Access 5: e129

25. A Heidari (2016) Pharmacokinetics and Experimental Therapeutic Study of DNA and Other Biomolecules Using Lasers: Advantages and Applications J Pharmacokinet Exp Ther 1: e005

26. A Heidari (2016) Determination of Ratio and Stability Constant of DNA/RNA in Human Cancer Cells and Cadmium Oxide (CdO) Nanoparticles Complexes Using Analytical Electrochemical and Spectroscopic Techniques. Insights Anal Electrochem 2: 1 
27. A Heidari (2016) Discriminate between Antibacterial and Non-Antibacterial Drugs Artificial Neutral Networks of a Multilayer Perceptron (MLP) Type Using a Set of Topological Descriptors. J Heavy Met Toxicity Dis 1:2

28. A Heidari (2016) Combined Theoretical and Computational Study of the Belousov-Zhabotinsky Chaotic Reaction and Curtius Rearrangement for Synthesis of Mechlorethamine, Cisplatin, Streptozotocin, Cyclophosphamide, Melphalan, Busulphan and BCNU as Anti-Cancer Drugs. Insights Med Phys 1:2

29. A Heidari (2016) A Translational Biomedical Approach to Structural Arrangement of Amino Acids' Complexes: A Combined Theoretical and Computational Study. Transl Biomed 7: 2

30. A Heidari (2016) Ab Initio and Density Functional Theory (DFT) Studies of Dynamic NMR Shielding Tensors and Vibrational Frequencies of DNA/RNA and Cadmium Oxide (CdO) Nanoparticles Complexes in Human Cancer Cells J Nanomedine Biotherapeutic Discov 6: e144

31. A Heidari (2016) Molecular Dynamics and Monte-Carlo Simulations for Replacement Sugars in Insulin Resistance, Obesity, LDL Cholesterol, Triglycerides, Metabolic Syndrome, Type 2 Diabetes and Cardiovascular Disease: A Glycobiological Study. J Glycobiol 5: e111

32. A Heidari (2016) Synthesis and Study of 5-[(Phenylsulfonyl)Amino]-1,3,4-Thiadiazole-2-Sulfonamide as Potential Anti-Pertussis Drug Using Chromatography and Spectroscopy Techniques. Transl Med (Sunnyvale) 6: e138

33. A Heidari (2016) Nitrogen, Oxygen, Phosphorus and Sulphur Heterocyclic Anti-Cancer Nano Drugs Separation in the Supercritical Fluid of Ozone (O3) Using SoaveRedlich-Kwong (SRK) and Pang-Robinson (PR) Equations. Electronic J Biol 12: 4

34. A Heidari (2016) An Analytical and Computational Infrared Spectroscopic Review of Vibrational Modes in Nucleic Acids. Austin J Anal Pharm Chem 3(1): 1058

35. A Heidari, C Brown (2016) Phase, Composition and Morphology Study and Analysis of Os-Pd/HfC Nanocomposites. Nano Res Appl 2: 1

36. A Heidari, C Brown (2016) Vibrational Spectroscopic Study of Intensities and Shifts of Symmetric Vibration Modes of
Ozone Diluted by Cumene. International Journal of Advanced Chemistry 4(1): 5-9

37. A Heidari (2016) Study of the Role of Anti-Cancer Molecules with Different Sizes for Decreasing Corresponding Bulk Tumor Multiple Organs or Tissues. Arch Can Res 4: 2

38. A Heidari (2016) Genomics and Proteomics Studies of Zolpidem, Necopidem, Alpidem, Saripidem, Miroprofen, Zolimidine, Olprinone and Abafungin as Anti-Tumor, Peptide Antibiotics, Antiviral and Central Nervous System (CNS) Drugs. J Data Mining Genomics \& Proteomics 7: e125

39. A Heidari (2016) Pharmacogenomics and Pharmacoproteomics Studies of Phosphodiesterase-5 (PDE5) Inhibitors and Paclitaxel Albumin-Stabilized Nanoparticles as Sandwiched Anti-Cancer Nano Drugs between Two DNA/RNA Molecules of Human Cancer Cells. J Pharmacogenomics Pharmacoproteomics 7: e153

40. A Heidari (2016) Biotranslational Medical and Biospectroscopic Studies of Cadmium Oxide (CdO) NanoparticlesDNA/RNA Straight and Cycle Chain Complexes as Potent Anti-Viral, Anti-Tumor and Anti-Microbial Drugs: A Clinical. Approach Transl Biomed 7: 2

41. A Heidari (2016) A Comparative Study on Simultaneous Determination and Separation of Adsorbed Cadmium Oxide (CdO) Nanoparticles on DNA/RNA of Human Cancer Cells Using Biospectroscopic Techniques and Dielectrophoresis (DEP) Method. Arch Can Res 4: 2

42. A Heidari (2016) Cheminformatics and System Chemistry of Cisplatin, Carboplatin, Nedaplatin, Oxaliplatin, Heptaplatin and Lobaplatin as Anti-Cancer Nano Drugs: A Combined Computational and Experimental Study. J Inform Data Min 1:3

43. A Heidari (2016) Linear and Non-Linear Quantitative Structure-Anti-Cancer-Activity Relationship (QSACAR) Study of Hydrous Ruthenium (IV) Oxide (RuO2) Nanoparticles as Non-Nucleoside Reverse Transcriptase Inhibitors (NNRTIs) and Anti-Cancer Nano Drugs. J Integr Oncol 5: e110

44. A Heidari (2016) Synthesis, Characterization and Biospectroscopic Studies of Cadmium Oxide (CdO) NanoparticlesNucleic Acids Complexes Absence of Soluble Polymer as a Protective Agent Using Nucleic Acids Condensation and 
Solution Reduction Method. J Nanosci Curr Res 1: e101

45. A Heidari (2016) Coplanarity and Collinearity of 4'-Dinonyl-2,2'-Bithiazole in One Domain of Bleomycin and Pingyangmycin to be Responsible for Binding of Cadmium Oxide (CdO) Nanoparticles to DNA/RNA Bidentate Ligands as Anti-Tumor Nano Drug. Int J Drug Dev \& Res 8: 007-008

46. A Heidari (2016) A Pharmacovigilance Study on Linear and Non-Linear Quantitative Structure (Chromatographic) Retention Relationships (QSRR) Models for the Prediction of Retention Time of Anti-Cancer Nano Drugs under Synchrotron Radiations. J Pharmacovigil 4: e161

47. A Heidari (2016) Nanotechnology in Preparation of Semipermeable Polymers. J Adv Chem Eng 6: 157

48. A Heidari (2016) A Gastrointestinal Study on Linear and Non-Linear Quantitative Structure (Chromatographic) Retention Relationships (QSRR) Models for Analysis 5-Aminosalicylates Nano Particles as Digestive System Nano Drugs under Synchrotron Radiations. J Gastrointest Dig Syst 6: e119

49. A Heidari (2016) DNA/RNA Fragmentation and Cytolysis in Human Cancer Cells Treated with Diphthamide Nano Particles Derivatives. Biomedical Data Mining 5: e102

50. A Heidari (2016) A Successful Strategy for the Prediction of Solubility in the Construction of Quantitative Structure-Activity Relationship (QSAR) and Quantitative Structure-Property Relationship (QSPR) under Synchrotron Radiations Using Genetic Function Approximation (GFA) Algorithm. J Mol Biol Biotechnol 1: 1

51. A Heidari (2016) Computational Study on Molecular Structures of C20, C60, C240, C540, C960, C2160 and C3840 Fullerene Nano Molecules under Synchrotron Radiations Using Fuzzy Logic. J Material Sci Eng 5: 282

52. A Heidari (2016) Graph Theoretical Analysis of Zigzag Polyhexamethylene Biguanide, Polyhexamethylene Adipamide, Polyhexamethylene Biguanide Gauze and Polyhexamethylene Biguanide Hydrochloride (PHMB) Boron Nitride Nanotubes (BNNTs), Amorphous Boron Nitride Nanotubes (a-BNNTs) and Hexagonal Boron Nitride Nanotubes (h-BNNTs). J Appl Computat Math 5: e143
53. A Heidari (2016) The Impact of High Resolution Imaging on Diagnosis. Int J Clin Med Imaging 3(6): 1000e101

54. A Heidari (2016) A Comparative Study of Conformational Behavior of Isotretinoin (13-Cis Retinoic Acid) and Tretinoin (All-Trans Retinoic Acid (ATRA)) Nano Particles as Anti-Cancer Nano Drugs under Synchrotron Radiations Using Hartree-Fock (HF) and Density Functional Theory (DFT) Methods. Insights in Biomed 1:2

55. A Heidari (2016) Advances in Logic, Operations and Computational Mathematics. J Appl Computat Math 5: 5

56. A Heidari (2016) Mathematical Equations in Predicting Physical Behavior. J Appl Computat Math 5: 5

57. A Heidari (2016) Chemotherapy a Last Resort for Cancer Treatment. Chemo Open Access 5: 4

58. A Heidari (2016) Separation and Pre-Concentration of Metal Cations-DNA/RNA Chelates Using Molecular Beam Mass Spectrometry with Tunable Vacuum Ultraviolet (VUV) Synchrotron Radiation and Various Analytical Methods. Mass Spectrom Purif Tech 2: e101

59. A Heidari (2016) Yoctosecond Quantitative Structure-Activity Relationship (QSAR) and Quantitative StructureProperty Relationship (QSPR) under Synchrotron Radiations Studies for Prediction of Solubility of Anti-Cancer Nano Drugs in Aqueous Solutions Using Genetic Function Approximation (GFA) Algorithm. Insight Pharm Res 1: 1

60. A Heidari (2016) Cancer Risk Prediction and Assessment in Human Cells under Synchrotron Radiations Using Quantitative Structure Activity Relationship (QSAR) and Quantitative Structure Properties Relationship (QSPR) Studies. Int J Clin Med Imaging 3: 516

61. A Heidari (2016) A Novel Approach to Biology. Electronic J Biol 12: 4

62. A Heidari (2016) Innovative Biomedical Equipment's for Diagnosis and Treatment. J Bioengineer \& Biomedical Sci 6: 2

63. A Heidari (2016) Integrating Precision Cancer Medicine into Healthcare, Medicare Reimbursement Changes and the Practice of Oncology: Trends in Oncology Medicine and Practices. J Oncol Med \& Pract 1: 2 
64. A Heidari (2016) Promoting Convergence in Biomedical and Biomaterials Sciences and Silk Proteins for Biomedical and Biomaterials Applications: An Introduction to Materials in Medicine and Bioengineering Perspectives. J Bioengineer \& Biomedical Sci 6: 3

65. A Heidari (2017) X-Ray Fluorescence and X-Ray Diffraction Analysis on Discrete Element Modeling of Nano Powder Metallurgy Processes in Optimal Container Design. J Powder Metall Min 6: 1

66. A Heidari (2017). Biomolecular Spectroscopy and Dynamics of Nano-Sized Molecules and Clusters as Cross-Linking-Induced Anti-Cancer and Immune-Oncology Nano Drugs Delivery in DNA/RNA of Human Cancer Cells' Membranes under Synchrotron Radiations: A Payload-Based Perspective. Arch Chem Res 1:2

67. A Heidari (2017) Deficiencies in Repair of Double-Standard DNA/RNA-Binding Molecules Identified in Many Types of Solid and Liquid Tumors Oncology in Human Body for Advancing Cancer Immunotherapy Using Computer Simulations and Data Analysis: Number of Mutations in a Synchronous Tumor Varies by Age and Type of Synchronous Cancer. J Appl Bioinforma Comput Biol 6: 1

68. A Heidari (2017) Electronic Coupling among the Five Nanomolecules Shuts Down Quantum Tunneling in the Presence and Absence of an Applied Magnetic Field for Indication of the Dimer or other Provide Different Influences on the Magnetic Behavior of Single Molecular Magnets (SMMs) as Qubits for Quantum Computing. Glob J Res Rev. 4: 2

69. A Heidari (2017) Polymorphism in Nano-Sized Graphene Ligand-Induced Transformation of Au38-xAgx/xCux(SPh-tBu)24 to Au36-xAgx/xCux(SPh-tBu)24 (x = 1-12) Nanomolecules for Synthesis of Au144-xAgx/xCux[(SR)60, (SC4)60, (SC6)60, (SC12)60, (PET)60, (p-MBA)60, (F)60, (Cl)60, (Br)60, (I)60, (At)60, (Uus)60 and (SC6H13)60] Nano Clusters as Anti-Cancer Nano Drugs. J Nanomater Mol Nanotechnol 6: 3

70. A Heidari (2017) Biomedical Resource Oncology and Data Mining to Enable Resource Discovery in Medical, Medicinal, Clinical, Pharmaceutical, Chemical and Translational Research and Their Applications in Cancer Research. Int J Biomed Data Min 6: e103
71. A Heidari (2017) Study of Synthesis, Pharmacokinetics, Pharmacodynamics, Dosing, Stability, Safety and Efficacy of Olympiadane Nanomolecules as Agent for Cancer Enzymotherapy, Immunotherapy, Chemotherapy, Radiotherapy, Hormone Therapy and Targeted Therapy under Synchrotorn Radiation. J Dev Drugs 6: e154

72. A Heidari (2017) A Novel Approach to Future Horizon of Top Seven Biomedical Research Topics to Watch in 2017: Alzheimer's, Ebola, Hypersomnia, Human Immunodeficiency Virus (HIV), Tuberculosis (TB), Microbiome/Antibiotic Resistance and Endovascular Stroke. J Bioengineer \& Biomedical Sci 7: e127

73. A Heidari (2017) Opinion on Computational Fluid Dynamics (CFD) Technique. Fluid Mech Open Acc 4: 157

74. A Heidari (2017) Concurrent Diagnosis of Oncology Influence Outcomes in Emergency General Surgery for Colorectal Cancer and Multiple Sclerosis (MS) Treatment Using Magnetic Resonance Imaging (MRI) and Au329(SR)84, Au329-xAgx(SR)84, Au144(SR)60, Au68(SR)36, Au30(SR)18, Au102(SPh)44, Au38(SPh)24, Au38(SC2H4Ph)24, Au21S(SAdm)15, Au36(pMBA)24 and Au25(pMBA)18 Nano Clusters. J Surgery Emerg Med 1: 21

75. A Heidari (2017) Developmental Cell Biology in Adult Stem Cells Death and Autophagy to Trigger a Preventive Allergic Reaction to Common Airborne Allergens under Synchrotron Radiation Using Nanotechnology for Therapeutic Goals in Particular Allergy Shots (Immunotherapy). Cell Biol (Henderson, NV) 6: 1

76. A Heidari (2017) Changing Metal Powder Characteristics for Elimination of the Heavy Metals Toxicity and Diseases in Disruption of Extracellular Matrix (ECM) Proteins Adjustment in Cancer Metastases Induced by Osteosarcoma, Chondrosarcoma, Carcinoid, Carcinoma, Ewing's Sarcoma, Fibrosarcoma and Secondary Hematopoietic Solid or Soft Tissue Tumors. J Powder Metall Min 6: 170

77. A Heidari (2017) Nanomedicine-Based Combination Anti-Cancer Therapy between Nucleic Acids and AntiCancer Nano Drugs in Covalent Nano Drugs Delivery Systems for Selective Imaging and Treatment of Human Brain Tumors Using Hyaluronic Acid, Alguronic Acid and Sodium Hyaluronate as Anti-Cancer Nano Drugs and Nucleic Acids Delivery under Synchrotron Radiation, Am J Drug Deliv 5: 2

Citation: Heidari A (2019). The Importance of Attenuated Total Reflectance Fourier Transform Infrared (ATR-FTIR) and Raman Biospectroscopy of Single-Walled Carbon Nanotubes (SWCNT) and Multi-Walled Carbon Nanotubes (MWCNT) in Interpreting Infrared and Raman Spectra of Human Cancer Cells, Tissues and Tumors. Oncogen 2(2): 7. 
78. A Heidari (2017) Clinical Trials of Dendritic Cell Therapies for Cancer Exposing Vulnerabilities in Human Cancer Cells' Metabolism and Metabolomics: New Discoveries, Unique Features Inform New Therapeutic Opportunities, Biotech's Bumpy Road to the Market and Elucidating the Biochemical Programs that Support Cancer Initiation and Progression. J Biol Med Science 1: e103

79. A Heidari (2017) The Design Graphene-Based Nanosheets as a New Nanomaterial in Anti-Cancer Therapy and Delivery of Chemotherapeutics and Biological Nano Drugs for Liposomal Anti-Cancer Nano Drugs and Gene Delivery. Br Biomed Bull 5: 305

80. A Heidari (2017) Integrative Approach to Biological Networks for Emerging Roles of Proteomics, Genomics and Transcriptomics in the Discovery and Validation of Human Colorectal Cancer Biomarkers from DNA/RNA Sequencing Data under Synchrotron Radiation. Transcriptomics 5: e117

81. A Heidari (2017) Elimination of the Heavy Metals Toxicity and Diseases in Disruption of Extracellular Matrix (ECM) Proteins and Cell Adhesion Intelligent Nanomolecules Adjustment in Cancer Metastases Using Metalloenzymes and under Synchrotron Radiation. Lett Health Biol Sci 2 (2): 1-4

82. A Heidari (2017) Treatment of Breast Cancer Brain Metastases through a Targeted Nanomolecule Drug Delivery System Based on Dopamine Functionalized MultiWall Carbon Nanotubes (MWCNTs) Coated with Nano Graphene Oxide (GO) and Protonated Polyaniline (PANI) in Situ During the Polymerization of Aniline Autogenic Nanoparticles for the Delivery of Anti-Cancer Nano Drugs under Synchrotron Radiation. Br J Res 4(3): 16

83. A Heidari (2017) Sedative, Analgesic and Ultrasound-Mediated Gastrointestinal Nano Drugs Delivery for Gastrointestinal Endoscopic Procedure, Nano Drug-Induced Gastrointestinal Disorders and Nano Drug Treatment of Gastric Acidity. Res Rep Gastroenterol 1: 1

84. A Heidari (2017) Synthesis, Pharmacokinetics, Pharmacodynamics, Dosing, Stability, Safety and Efficacy of Orphan Nano Drugs to Treat High Cholesterol and Related Conditions and to Prevent Cardiovascular Disease under Synchrotron Radiation. J Pharm Sci Emerg Drugs 5: 1
85. A Heidari (2017) Non-Linear Compact Proton Synchrotrons to Improve Human Cancer Cells and Tissues Treatments and Diagnostics through Particle Therapy Accelerators with Monochromatic Microbeams. J Cell Biol Mol Sci 2(1): 1-5

86. A Heidari (2017) Design of Targeted Metal Chelation Therapeutics Nanocapsules as Colloidal Carriers and Blood-Brain Barrier (BBB) Translocation to Targeted Deliver Anti-Cancer Nano Drugs into the Human Brain to Treat Alzheimer's Disease under Synchrotron Radiation. J Nanotechnol Material Sci 4(2): 1-5

87. R. Gobato, A. Heidari, Calculations Using Quantum Chemistry for Inorganic Molecule Simulation BeLi2SeSi, Science Journal of Analytical Chemistry, Vol. 5, No. 6, Pages 76-85, 2017.

88. A Heidari (2017) Different High-Resolution Simulations of Medical, Medicinal, Clinical, Pharmaceutical and Therapeutics Oncology of Human Lung Cancer Translational Anti-Cancer Nano Drugs Delivery Treatment Process under Synchrotron and X-Ray Radiations. J Med Oncol 1(1): 1

89. A Heidari (2017) A Modern Ethnomedicinal Technique for Transformation, Prevention and Treatment of Human Malignant Gliomas Tumors into Human Benign Gliomas Tumors under Synchrotron Radiation. Am J Ethnomed 4(1): 10

90. A Heidari (2017) Active Targeted Nanoparticles for AntiCancer Nano Drugs Delivery across the Blood-Brain Barrier for Human Brain Cancer Treatment, Multiple Sclerosis (MS) and Alzheimer's Diseases Using Chemical Modifications of Anti-Cancer Nano Drugs or Drug-Nanoparticles through Zika Virus (ZIKV) Nanocarriers under Synchrotron Radiation. J Med Chem Toxicol 2(3): 1-5

91. A Heidari (2017) Investigation of Medical, Medicinal, Clinical and Pharmaceutical Applications of Estradiol, Mestranol (Norlutin), Norethindrone (NET), Norethisterone Acetate (NETA), Norethisterone Enanthate (NETE) and Testosterone Nanoparticles as Biological Imaging, Cell Labeling, Anti-Microbial Agents and Anti-Cancer Nano Drugs in Nanomedicines Based Drug Delivery Systems for Anti-Cancer Targeting and Treatment. Parana Journal of Science and Education (PJSE) 3(4): 10-19 
92. A Heidari (2017) A Comparative Computational and Experimental Study on Different Vibrational Biospectroscopy Methods, Techniques and Applications for Human Cancer Cells in Tumor Tissues Simulation, Modeling, Research, Diagnosis and Treatment. Open J Anal Bioanal Chem 1(1): 014-020

93. A Heidari (2017) Combination of DNA/RNA Ligands and Linear/Non-Linear Visible-Synchrotron Radiation-Driven N-Doped Ordered Mesoporous Cadmium Oxide (CdO) Nanoparticles Photocatalysts Channels Resulted in an Interesting Synergistic Effect Enhancing Catalytic Anti-Cancer Activity. Enz Eng 6: 1

94. A Heidari (2017) Modern Approaches in Designing Ferritin, Ferritin Light Chain, Transferrin, Beta-2 Transferrin and Bacterioferritin-Based Anti-Cancer Nano Drugs Encapsulating Nanosphere as DNA-Binding Proteins from Starved Cells (DPS). Mod Appro Drug Des 1(1). MADD.000504

95. A Heidari (2017) Potency of Human Interferon $\beta-1 \mathrm{a}$ and Human Interferon $\beta-1 b$ in Enzymotherapy, Immunotherapy, Chemotherapy, Radiotherapy, Hormone Therapy and Targeted Therapy of Encephalomyelitis Disseminate/Multiple Sclerosis (MS) and Hepatitis A, B, C, D, E, F and G Virus Enter and Targets Liver Cells. J Proteomics Enzymol 6: 1

96. A Heidari (2017) Transport Therapeutic Active Targeting of Human Brain Tumors Enable Anti-Cancer Nanodrugs Delivery across the Blood-Brain Barrier (BBB) to Treat Brain Diseases Using Nanoparticles and Nanocarriers under Synchrotron Radiation. J Pharm Pharmaceutics 4(2): 1-5

97. A Heidari and C Brown (2017) Combinatorial Therapeutic Approaches to DNA/RNA and Benzylpenicillin (Penicillin G), Fluoxetine Hydrochloride (Prozac and Sarafem), Propofol (Diprivan), Acetylsalicylic Acid (ASA) (Aspirin), Naproxen Sodium (Aleve and Naprosyn) and Dextromethamphetamine Nanocapsules with Surface Conjugated DNA/ RNA to Targeted Nano Drugs for Enhanced Anti-Cancer Efficacy and Targeted Cancer Therapy Using Nano Drugs Delivery Systems. Ann Adv Chem 1(2): 061-069

98. A Heidari (2017) High-Resolution Simulations of Human Brain Cancer Translational Nano Drugs Delivery Treatment Process under Synchrotron Radiation. J Transl Res. 1 (1): $1-3$

99. A Heidari (2017) Investigation of Anti-Cancer Nano Drugs' Effects' Trend on Human Pancreas Cancer Cells and Tis- sues Prevention, Diagnosis and Treatment Process under Synchrotron and X-Ray Radiations with the Passage of Time Using Mathematica. Current Trends Anal Bioanal Chem 1(1): 36-41

100.A Heidari (2017) Pros and Cons Controversy on Molecular Imaging and Dynamics of Double-Standard DNA/RNA of Human Preserving Stem Cells-Binding Nano Molecules with Androgens/Anabolic Steroids (AAS) or Testosterone Derivatives through Tracking of Helium-4 Nucleus (Alpha Particle) Using Synchrotron Radiation. Arch Biotechnol Biomed 1(1): 067-0100

101.A Heidari (2017) Visualizing Metabolic Changes in Probing Human Cancer Cells and Tissues Metabolism Using Vivo $1 \mathrm{H}$ or Proton NMR, 13C NMR, 15N NMR and 31P NMR Spectroscopy and Self-Organizing Maps under Synchrotron Radiation. SOJ Mater Sci Eng 5(2): 1-6

102.A Heidari (2017) Cavity Ring-Down Spectroscopy (CRDS), Circular Dichroism Spectroscopy, Cold Vapour Atomic Fluorescence Spectroscopy and Correlation Spectroscopy Comparative Study on Malignant and Benign Human Cancer Cells and Tissues with the Passage of Time under Synchrotron Radiation. Enliven: Challenges Cancer Detect Ther 4(2): e001

103.A Heidari (2017) Laser Spectroscopy, Laser-Induced Breakdown Spectroscopy and Laser-Induced Plasma Spectroscopy Comparative Study on Malignant and Benign Human Cancer Cells and Tissues with the Passage of Time under Synchrotron Radiation. Int J Hepatol Gastroenterol 3(4): 079-084

104.A Heidari (2017) Time-Resolved Spectroscopy and TimeStretch Spectroscopy Comparative Study on Malignant and Benign Human Cancer Cells and Tissues with the Passage of Time under Synchrotron Radiation. Enliven: Pharmacovigilance and Drug Safety 4(2): e001.

105.A Heidari (2017) Overview of the Role of Vitamins in Reducing Negative Effect of Decapeptyl (Triptorelin Acetate or Pamoate Salts) on Prostate Cancer Cells and Tissues in Prostate Cancer Treatment Process through Transformation of Malignant Prostate Tumors into Benign Prostate Tumors under Synchrotron Radiation. Open J Anal Bioanal Chem 1(1): 021-026

106.A Heidari (2017) Electron Phenomenological Spectroscopy, Electron Paramagnetic Resonance (EPR) Spectroscopy

Citation: Heidari A (2019). The Importance of Attenuated Total Reflectance Fourier Transform Infrared (ATR-FTIR) and Raman Biospectroscopy of Single-Walled Carbon Nanotubes (SWCNT) and Multi-Walled Carbon Nanotubes (MWCNT) in Interpreting Infrared and Raman Spectra of Human Cancer Cells, Tissues and Tumors. Oncogen 2(2): 7. 
and Electron Spin Resonance (ESR) Spectroscopy Comparative Study on Malignant and Benign Human Cancer Cells and Tissues with the Passage of Time under Synchrotron Radiation. Austin J Anal Pharm Chem 4(3): 1091

107.A Heidari (2017) Therapeutic Nanomedicine Different High-Resolution Experimental Images and Computational Simulations for Human Brain Cancer Cells and Tissues Using Nanocarriers Deliver DNA/RNA to Brain Tumors under Synchrotron Radiation with the Passage of Time Using Mathematica and MATLAB. Madridge J Nano Tech. Sci. 2(2): 77-83

108. A Heidari (2017) A Consensus and Prospective Study on Restoring Cadmium Oxide (CdO) Nanoparticles Sensitivity in Recurrent Ovarian Cancer by Extending the Cadmium Oxide (CdO) Nanoparticles-Free Interval Using Synchrotron Radiation Therapy as Antibody-Drug Conjugate for the Treatment of Limited-Stage Small Cell Diverse Epithelial Cancers. Cancer Clin Res Rep 1: 2, e001

109. A Heidari (2017) A Novel and Modern Experimental Imaging and Spectroscopy Comparative Study on Malignant and Benign Human Cancer Cells and Tissues with the Passage of Time under White Synchrotron Radiation. Cancer Sci Res Open Access 4(2): 1-8.

110.A Heidari (2017) Different High-Resolution Simulations of Medical, Medicinal, Clinical, Pharmaceutical and Therapeutics Oncology of Human Breast Cancer Translational Nano Drugs Delivery Treatment Process under Synchrotron and X-Ray Radiations. J Oral Cancer Res 1(1): 12-17

111.A Heidari (2017) Vibrational Decihertz (dHz), Centihertz $(\mathrm{cHz})$, Millihertz $(\mathrm{mHz})$, Microhertz $(\mu \mathrm{Hz})$, Nanohertz $(\mathrm{nHz})$, Picohertz (pHz), Femtohertz (fHz), Attohertz (aHz), Zeptohertz $(\mathrm{zHz})$ and Yoctohertz (yHz) Imaging and Spectroscopy Comparative Study on Malignant and Benign Human Cancer Cells and Tissues under Synchrotron Radiation. International Journal of Biomedicine. 7(4): 335-340

112.A Heidari (2017) Force Spectroscopy and Fluorescence Spectroscopy Comparative Study on Malignant and Benign Human Cancer Cells and Tissues with the Passage of Time under Synchrotron Radiation. EC Cancer 2(5): 239246

113. A Heidari (2017) Photoacoustic Spectroscopy, Photoemission Spectroscopy and Photothermal Spectroscopy Com- parative Study on Malignant and Benign Human Cancer Cells and Tissues with the Passage of Time under Synchrotron Radiation. BAOJ Cancer Res Ther 3(3): 045-052

114.A Heidari (2017) J-Spectroscopy, Exchange Spectroscopy (EXSY), Nucle $\neg$ ar Overhauser Effect Spectroscopy (NOESY) and Total Correlation Spectroscopy (TOCSY) Comparative Study on Malignant and Benign Human Cancer Cells and Tissues under Synchrotron Radiation. EMS Eng Sci J 1(2): 006-013

115.A Heidari (2017) Neutron Spin Echo Spectroscopy and Spin Noise Spectroscopy Comparative Study on Malignant and Benign Human Cancer Cells and Tissues with the Passage of Time under Synchrotron Radiation. Int J Biopharm Sci 1: 103-107

116.A Heidari (2017) Vibrational Decahertz (daHz), Hectohertz $(\mathrm{hHz})$, Kilohertz (kHz), Megahertz (MHz), Gigahertz (GHz), Terahertz (THz), Petahertz (PHz), Exahertz (EHz), Zettahertz ( $\mathrm{ZHz})$ and Yottahertz ( $\mathrm{YHz}$ ) Imaging and Spectroscopy Comparative Study on Malignant and Benign Human Cancer Cells and Tissues under Synchrotron Radiation. Madridge J Anal Sci Instrum 2(1): 41-46

117.A Heidari (2018) Two-Dimensional Infrared Correlation Spectroscopy, Linear Two-Dimensional Infrared Spectroscopy and Non-Linear Two-Dimensional Infrared Spectroscopy Comparative Study on Malignant and Benign Human Cancer Cells and Tissues under Synchrotron Radiation with the Passage of Time. J Mater Sci Nanotechnol 6(1): 101

118.A Heidari (2018) Fourier Transform Infrared (FTIR) Spectroscopy, Near-Infrared Spectroscopy (NIRS) and Mid-Infrared Spectroscopy (MIRS) Comparative Study on Malignant and Benign Human Cancer Cells and Tissues under Synchrotron Radiation with the Passage of Time. Int J Nanotechnol Nanomed 3(1): 1-6

119.A Heidari (2018) Infrared Photo Dissociation Spectroscopy and Infrared Correlation Table Spectroscopy Comparative Study on Malignant and Benign Human Cancer Cells and Tissues under Synchrotron Radiation with the Passage of Time. Austin Pharmacol Pharm 3(1): 1011

120.A Heidari (2017) Novel and Transcendental Prevention, Diagnosis and Treatment Strategies for Investigation of Interaction among Human Blood Cancer Cells, Tissues, Tu- 
mors and Metastases with Synchrotron Radiation under Anti-Cancer Nano Drugs Delivery Efficacy Using MATLAB Modeling and Simulation. Madridge J Nov Drug Res 1(1): $18-24$

121. A Heidari (2018) Comparative Study on Malignant and Benign Human Cancer Cells and Tissues with the Passage of Time under Synchrotron Radiation. Open Access J Trans Med Res 2(1): 00026-00032

122.M R R Gobato, R Gobato and A Heidari (2018) Planting of Jaboticaba Trees for Landscape Repair of Degraded Area. Landscape Architecture and Regional Planning 3(1): 1-9

123.A Heidari (2018) Fluorescence Spectroscopy, Phosphorescence Spectroscopy and Luminescence Spectroscopy Comparative Study on Malignant and Benign Human Cancer Cells and Tissues under Synchrotron Radiation with the Passage of Time. SM J Clin. Med. Imaging 4(1): 1018

124. A Heidari (2018) Nuclear Inelastic Scattering Spectroscopy (NISS) and Nuclear Inelastic Absorption Spectroscopy (NIAS) Comparative Study on Malignant and Benign Human Cancer Cells and Tissues under Synchrotron Radiation. Int J Pharm Sci 2(1): 1-14

125.A Heidari (2018) X-Ray Diffraction (XRD), Powder X-Ray Diffraction (PXRD) and Energy-Dispersive X-Ray Diffraction (EDXRD) Comparative Study on Malignant and Benign Human Cancer Cells and Tissues under Synchrotron Radiation. J Oncol Res 2(1): 1-14

126. A Heidari (2018) Correlation Two-Dimensional Nuclear Magnetic Reso $\neg$ nance (NMR) (2D-NMR) (COSY) Imaging and Spectrosco $\neg$ py Comparative Study on Malignant and Benign Human Cancer Cells and Tissues under Synchrotron Radiation. EMS Can Sci 2(1): 001-007

127.A Heidari (2018) Thermal Spectroscopy, Photothermal Spectroscopy, Thermal Microspectroscopy, Photothermal Microspectroscopy, Thermal Macrospectroscopy and Photothermal Macrospectroscopy Comparative Study on Malignant and Benign Human Cancer Cells and Tissues with the Passage of Time under Synchrotron Radiation. SM J Biometrics Biostat 3(1): 1024

128. A Heidari (2018) A Modern and Comprehensive Experimental Biospectroscopic Comparative Study on Human Common Cancers' Cells, Tissues and Tumors before and after Synchrotron Radiation Therapy. Open Acc J Oncol Med 1:1

129.A Heidari (2018) Heteronuclear Correlation Experiments such as Heteronuclear Single-Quantum Correlation Spectroscopy (HSQC), Heteronuclear Multiple-Quantum Correlation Spectroscopy (HMQC) and Heteronuclear Multiple-Bond Correlation Spectroscopy (HMBC) Comparative Study on Malignant and Benign Human Endocrinology and Thyroid Cancer Cells and Tissues under Synchrotron Radiation. J Endocrinol Thyroid Res 3(1): 555603

130.A Heidari (2018) Nuclear Resonance Vibrational Spectroscopy (NRVS), Nuclear Inelastic Scattering Spectroscopy (NISS), Nuclear Inelastic Absorption Spectroscopy (NIAS) and Nuclear Resonant Inelastic X-Ray Scattering Spectroscopy (NRIXSS) Comparative Study on Malignant and Benign Human Cancer Cells and Tissues under Synchrotron Radiation. Int J Bioorg Chem Mol Biol 6(1e): 1-5

131. A Heidari (2018) A Novel and Modern Experimental Approach to Vibrational Circular Dichroism Spectroscopy and Video Spectroscopy Comparative Study on Malignant and Benign Human Cancer Cells and Tissues with the Passage of Time under White and Monochromatic Synchrotron Radiation. Glob J Endocrinol Metab 1(3): 000514000519

132. A Heidari (2018) Pros and Cons Controversy on Heteronuclear Correlation Experiments such as Heteronuclear Single-Quantum Correlation Spectroscopy (HSQC), Heteronuclear Multiple-Quantum Correlation Spectroscopy (HMQC) and Heteronuclear Multiple-Bond Correlation Spectroscopy (HMBC) Comparative Study on Malignant and Benign Human Cancer Cells and Tissues under Synchrotron Radiation. EMS Pharma J 1(1): 002-008

133. A Heidari (2018) A Modern Comparative and Comprehensive Experimental Biospectroscopic Study on Different Types of Infrared Spectroscopy of Malignant and Benign Human Cancer Cells and Tissues with the Passage of Time under Synchrotron Radiation. J Analyt Molecul Tech 3(1): 8

134.A Heidari (2018) Investigation of Cancer Types Using Synchrotron Technology for Proton Beam Therapy: An Experimental Biospectroscopic Comparative Study. European Modern Studies Journal 2(1): 13-29

Citation: Heidari A (2019). The Importance of Attenuated Total Reflectance Fourier Transform Infrared (ATR-FTIR) and Raman Biospectroscopy of Single-Walled Carbon Nanotubes (SWCNT) and Multi-Walled Carbon Nanotubes (MWCNT) in Interpreting Infrared and Raman Spectra of Human Cancer Cells, Tissues and Tumors. Oncogen 2(2): 7. 
135. A Heidari (2018) Saturated Spectroscopy and Unsaturated Spectroscopy Comparative Study on Malignant and Benign Human Cancer Cells and Tissues with the Passage of Time under Synchrotron Radiation. Imaging J Clin Medical Sci 5(1): 001-007

136. A Heidari (2018) Small-Angle Neutron Scattering (SANS) and Wide-Angle X-Ray Diffraction (WAXD) Comparative Study on Malignant and Benign Human Cancer Cells and Tissues under Synchrotron Radiation. Int J Bioorg Chem Mol Biol 6(2e): 1-6

137.A Heidari (2018) Investigation of Bladder Cancer, Breast Cancer, Colorectal Cancer, Endometrial Cancer, Kidney Cancer, Leukemia, Liver, Lung Cancer, Melanoma, NonHodgkin Lymphoma, Pancreatic Cancer, Prostate Cancer, Thyroid Cancer and Non-Melanoma Skin Cancer Using Synchrotron Technology for Proton Beam Therapy: An Experimental Biospectroscopic Comparative Study. Ther Res Skin Dis 1(1)

138. A Heidari (2018) Attenuated Total Reflectance Fourier Transform Infrared (ATR-FTIR) Spectroscopy, Micro-Attenuated Total Reflectance Fourier Transform Infrared (Micro-ATR-FTIR) Spectroscopy and Macro-Attenuated Total Reflectance Fourier Transform Infrared (Macro-ATR-FTIR) Spectroscopy Comparative Study on Malignant and Benign Human Cancer Cells and Tissues under Synchrotron Radiation with the Passage of Time. International Journal of Chemistry Papers 2(1): 1-12

139.A Heidari (2018) Mössbauer Spectroscopy, Mössbauer Emission Spectroscopy and 57Fe Mössbauer Spectroscopy Comparative Study on Malignant and Benign Human Cancer Cells and Tissues under Synchrotron Radiation. Acta Scientific Cancer Biology 2(3): 17-20

140. A Heidari (2018) Comparative Study on Malignant and Benign Human Cancer Cells and Tissues under Synchrotron Radiation with the Passage of Time. Organic \& Medicinal Chem IJ 6(1): 555676

141. A Heidari (2018) Correlation Spectroscopy, Exclusive Correlation Spectroscopy and Total Correlation Spectroscopy Comparative Study on Malignant and Benign Human AIDS-Related Cancers Cells and Tissues with the Passage of Time under Synchrotron Radiation. Int J Bioanal Biomed 2(1): 001-007
142.A Heidari (2018) Biomedical Instrumentation and Applications of Biospectroscopic Methods and Techniques in Malignant and Benign Human Cancer Cells and Tissues Studies under Synchrotron Radiation and Anti-Cancer Nano Drugs Delivery. Am J Nanotechnol Nanomed 1(1): 001-009

143. A Heidari (2018) Vivo $1 \mathrm{H}$ or Proton NMR, $13 \mathrm{C}$ NMR, $15 \mathrm{~N}$ NMR and 31P NMR Spectroscopy Comparative Study on Malignant and Benign Human Cancer Cells and Tissues under Synchrotron Radiation. Ann Biomet Biostat 1(1): 1001

144.A Heidari (2018) Grazing-Incidence Small-Angle Neutron Scattering (GISANS) and Grazing-Incidence X-Ray Diffraction (GIXD) Comparative Study on Malignant and Benign Human Cancer Cells, Tissues and Tumors under Synchrotron Radiation. Ann Cardiovasc Surg 1(2): 1006

145. A Heidari (2018) Adsorption Isotherms and Kinetics of Multi-Walled Carbon Nanotubes (MWCNTs), Boron Nitride Nanotubes (BNNTs), Amorphous Boron Nitride Nanotubes (a-BNNTs) and Hexagonal Boron Nitride Nanotubes (h-BNNTs) for Eliminating Carcinoma, Sarcoma, Lymphoma, Leukemia, Germ Cell Tumor and Blastoma Cancer Cells and Tissues. Clin Med Rev Case Rep 5: 201

146. A Heidari (2018) Correlation Spectroscopy (COSY), Exclusive Correlation Spectroscopy (ECOSY), Total Correlation Spectroscopy (TOCSY), Incredible Natural-Abundance Double-Quantum Transfer Experiment (INADEQUATE), Heteronuclear Single-Quantum Correlation Spectroscopy (HSQC), Heteronuclear Multiple-Bond Correlation Spectroscopy (HMBC), Nuclear Overhauser Effect Spectroscopy (NOESY) and Rotating Frame Nuclear Overhauser Effect Spectroscopy (ROESY) Comparative Study on Malignant and Benign Human Cancer Cells and Tissues under Synchrotron Radiation. Acta Scientific Pharmaceutical Sciences 2(5): 30-35

147.A Heidari (2018) Small-Angle X-Ray Scattering (SAXS), Ultra-Small Angle X-Ray Scattering (USAXS), Fluctuation X-Ray Scattering (FXS), Wide-Angle X-Ray Scattering (WAXS), Grazing-Incidence Small-Angle X-Ray Scattering (GISAXS), Grazing-Incidence Wide-Angle X-Ray Scattering (GIWAXS), Small-Angle Neutron Scattering (SANS), Grazing-Incidence Small-Angle Neutron Scattering (GISANS), X-Ray Diffraction (XRD), Powder X-Ray Diffraction (PXRD), Wide-Angle $X$-Ray Diffraction (WAXD),

Citation: Heidari A (2019). The Importance of Attenuated Total Reflectance Fourier Transform Infrared (ATR-FTIR) and Raman Biospectroscopy of Single-Walled Carbon Nanotubes (SWCNT) and Multi-Walled Carbon Nanotubes (MWCNT) in Interpreting Infrared and Raman Spectra of Human Cancer Cells, Tissues and Tumors. Oncogen 2(2): 7. 
Grazing-Incidence X-Ray Diffraction (GIXD) and EnergyDispersive X-Ray Diffraction (EDXRD) Comparative Study on Malignant and Benign Human Cancer Cells and Tissues under Synchrotron Radiation. Oncol Res Rev 1(1): 1-10

148. A Heidari (2018) Pump-Probe Spectroscopy and Transient Grating Spectroscopy Comparative Study on Malignant and Benign Human Cancer Cells and Tissues with the Passage of Time under Synchrotron Radiation. Adv Material Sci Engg 2(1): 1-7

149.A Heidari (2018) Grazing-Incidence Small-Angle X-Ray Scattering (GISAXS) and Grazing-Incidence Wide-Angle X-Ray Scattering (GIWAXS) Comparative Study on Malignant and Benign Human Cancer Cells and Tissues under Synchrotron Radiation. Insights Pharmacol Pharm Sci 1 (1): 1-8

150.A Heidari (2018) Acoustic Spectroscopy, Acoustic Resonance Spectroscopy and Auger Spectroscopy Comparative Study on Anti-Cancer Nano Drugs Delivery in Malignant and Benign Human Cancer Cells and Tissues with the Passage of Time under Synchrotron Radiation. Nanosci Technol 5(1): 1-9

151.A Heidari (2018) Niobium, Technetium, Ruthenium, Rhodium, Hafnium, Rhenium, Osmium and Iridium lons Incorporation into the Nano Polymeric Matrix (NPM) by Immersion of the Nano Polymeric Modified Electrode (NPME) as Molecular Enzymes and Drug Targets for Human Cancer Cells, Tissues and Tumors Treatment under Synchrotron and Synchrocyclotron Radiations. Nanomed Nanotechnol 3(2): 000138

152.A Heidari (2018) Homonuclear Correlation Experiments such as Homonuclear Single-Quantum Correlation Spectroscopy (HSQC), Homonuclear Multiple-Quantum Correlation Spectroscopy (HMQC) and Homonuclear Multiple-Bond Correlation Spectroscopy (HMBC) Comparative Study on Malignant and Benign Human Cancer Cells and Tissues under Synchrotron Radiation. Austin J Proteomics Bioinform \& Genomics 5(1): 1024

153.A Heidari (2018) Atomic Force Microscopy Based Infrared (AFM-IR) Spectroscopy and Nuclear Resonance Vibrational Spectroscopy Comparative Study on Malignant and Benign Human Cancer Cells and Tissues under Synchrotron Radiation with the Passage of Time. J Appl Biotechnol Bioeng 5(3): 142-148
154.A Heidari (2018) Time-Dependent Vibrational Spectral Analysis of Malignant and Benign Human Cancer Cells and Tissues under Synchrotron Radiation. J Cancer Oncol 2(2): 000124

155.A Heidari (2018) Palauamine and Olympiadane Nano Molecules Incorporation into the Nano Polymeric Matrix (NPM) by Immersion of the Nano Polymeric Modified Electrode (NPME) as Molecular Enzymes and Drug Targets for Human Cancer Cells, Tissues and Tumors Treatment under Synchrotron and Synchrocyclotron Radiations. Arc Org Inorg Chem Sci 3(1)

156. R Gobato and A Heidari (2018) Infrared Spectrum and Sites of Action of Sanguinarine by Molecular Mechanics and ab initio Methods. International Journal of Atmospheric and Oceanic Sciences 2(1): 1-9

157.A Heidari (2018) Angelic Acid, Diabolic Acids, Draculin and Miraculin Nano Molecules Incorporation into the Nano Polymeric Matrix (NPM) by Immersion of the Nano Polymeric Modified Electrode (NPME) as Molecular Enzymes and Drug Targets for Human Cancer Cells, Tissues and Tumors Treatment Under Synchrotron and Synchrocyclotron Radiations. Med \& Analy Chem Int J 2(1): 000111

158.A Heidari (2018) Gamma Linolenic Methyl Ester, 5-Heptadeca-5,8,11-Trienyl 1,3,4-Oxadiazole-2-Thiol, Sulphoquinovosyl Diacyl Glycerol, Ruscogenin, Nocturnoside B, Protodioscine B, Parquisoside-B, Leiocarposide, Narangenin, 7-Methoxy Hespertin, Lupeol, Rosemariquinone, Rosmanol and Rosemadiol Nano Molecules Incorporation into the Nano Polymeric Matrix (NPM) by Immersion of the Nano Polymeric Modified Electrode (NPME) as Molecular Enzymes and Drug Targets for Human Cancer Cells, Tissues and Tumors Treatment under Synchrotron and Synchrocyclotron Radiations. Int J Pharma Anal Acta 2(1): 007-014

159.A Heidari (2018) Fourier Transform Infrared (FTIR) Spectroscopy, Attenuated Total Reflectance Fourier Transform Infrared (ATR-FTIR) Spectroscopy, Micro-Attenuated Total Reflectance Fourier Transform Infrared (Micro-ATR-FTIR) Spectroscopy, Macro-Attenuated Total Reflectance Fourier Transform Infrared (Macro-ATR-FTIR) Spectroscopy, Two-Dimensional Infrared Correlation Spectroscopy, Linear Two-Dimensional Infrared Spectroscopy, Non-Linear Two-Dimensional Infrared Spectroscopy, Atomic Force Microscopy Based Infrared (AFM-IR) Spectroscopy, Infra-

Citation: Heidari A (2019). The Importance of Attenuated Total Reflectance Fourier Transform Infrared (ATR-FTIR) and Raman Biospectroscopy of Single-Walled Carbon Nanotubes (SWCNT) and Multi-Walled Carbon Nanotubes (MWCNT) in Interpreting Infrared and Raman Spectra of Human Cancer Cells, Tissues and Tumors. Oncogen 2(2): 7. 
red Photodissociation Spectroscopy, Infrared Correlation Table Spectroscopy, Near-Infrared Spectroscopy (NIRS), Mid-Infrared Spectroscopy (MIRS), Nuclear Resonance Vibrational Spectroscopy, Thermal Infrared Spectroscopy and Photothermal Infrared Spectroscopy Comparative Study on Malignant and Benign Human Cancer Cells and Tissues under Synchrotron Radiation with the Passage of Time. Glob Imaging Insights 3(2): 1-14

160.A Heidari (2018) Heteronuclear Single-Quantum Correlation Spectroscopy (HSQC) and Heteronuclear Multiple-Bond Correlation Spectroscopy (HMBC) Comparative Study on Malignant and Benign Human Cancer Cells, Tissues and Tumors under Synchrotron and Synchrocyclotron Radiations. Chronicle of Medicine and Surgery 2.3: 144-156

161.A Heidari (2018) Tetrakis [3, 5-bis (Trifluoromethyl) Phenyl] Borate (BARF)-Enhanced Precatalyst Preparation Stabilization and Initiation (EPPSI) Nano Molecules. Medical Research and Clinical Case Reports 2.1: 113-126

162.A Heidari (2018) Sydnone, Münchnone, Montréalone, Mogone, Montelukast, Quebecol and Palau'amine-Enhanced Precatalyst Preparation Stabilization and Initiation (EPPSI) Nano Molecules. Sur Cas Stud Op Acc J 1(3)

163.A Heidari (2018) Fornacite, Orotic Acid, Rhamnetin, Sodium Ethyl Xanthate (SEX) and Spermine (Spermidine or Polyamine) Nanomolecules Incorporation into the Nanopolymeric Matrix (NPM). International Journal of Biochemistry and Biomolecules 4(1): 1-19

164.A Heidari and R. Gobato (2018) Putrescine, Cadaverine, Spermine and Spermidine-Enhanced Precatalyst Preparation Stabilization and Initiation (EPPSI) Nano Molecules. Parana Journal of Science and Education (PJSE) 4(5) :1-14

165. A Heidari (2018) Cadaverine (1,5-Pentanediamine or Pentamethylenediamine), Diethyl Azodicarboxylate (DEAD or DEADCAT) and Putrescine (Tetramethylenediamine) Nano Molecules Incorporation into the Nano Polymeric Matrix (NPM) by Immersion of the Nano Polymeric Modified Electrode (NPME) as Molecular Enzymes and Drug Targets for Human Cancer Cells, Tissues and Tumors Treatment under Synchrotron and Synchrocyclotron Radiations. Hiv and Sexual Health Open Access Open Journal 1(1): 4-11
166.A Heidari (2018) Improving the Performance of NanoEndofullerenes in Polyaniline Nanostructure-Based Biosensors by Covering Californium Colloidal Nanoparticles with Multi-Walled Carbon Nanotubes. Journal of Advances in Nanomaterials 3(1): 1-28

167.R Gobato and A Heidari (2018) Molecular Mechanics and Quantum Chemical Study on Sites of Action of Sanguinarine Using Vibrational Spectroscopy Based on Molecular Mechanics and Quantum Chemical Calculations. Malaysian Journal of Chemistry 20 (1): 1-23

168.A Heidari (2018) Vibrational Biospectroscopic Studies on Anti-cancer Nanopharmaceuticals (Part I). Malaysian Journal of Chemistry 20(1): 33-73

169.A Heidari (2018) Vibrational Biospectroscopic Studies on Anti-cancer Nanopharmaceuticals (Part II). Malaysian Journal of Chemistry 20(1): 74-117

170.A Heidari, Uranocene $(\mathrm{U}(\mathrm{C} 8 \mathrm{H} 8) 2)$ and Bis(Cyclooctatetraene)Iron (Fe(C8H8)2 or Fe(COT)2)-Enhanced Precatalyst Preparation Stabilization and Initiation (EPPSI) Nano Molecules. Chemistry Reports 1(2):1-16

171.A Heidari (2018) Biomedical Systematic and Emerging Technological Study on Human Malignant and Benign Cancer Cells and Tissues Biospectroscopic Analysis under Synchrotron Radiation. Glob Imaging Insights 3(3): 1-7

172.A Heidari (2018) Deep-Level Transient Spectroscopy and X-Ray Photoelectron Spectroscopy (XPS) Comparative Study on Malignant and Benign Human Cancer Cells and Tissues with the Passage of Time under Synchrotron Radiation. Res Dev Material Sci 7(2): 000659

173.A Heidari (2018) C70-Carboxyfullerenes Nano Molecules Incorporation into the Nano Polymeric Matrix (NPM) by Immersion of the Nano Polymeric Modified Electrode (NPME) as Molecular Enzymes and Drug Targets for Human Cancer Cells, Tissues and Tumors Treatment under Synchrotron and Synchrocyclotron Radiations. Glob Imaging Insights 3(3): 1-7

174.A Heidari (2018) The Effect of Temperature on Cadmium Oxide (CdO) Nanoparticles Produced by Synchrotron Radiation in the Human Cancer Cells, Tissues and Tumors. International Journal of Advanced Chemistry 6(2): 140-156

Citation: Heidari A (2019). The Importance of Attenuated Total Reflectance Fourier Transform Infrared (ATR-FTIR) and Raman Biospectroscopy of Single-Walled Carbon Nanotubes (SWCNT) and Multi-Walled Carbon Nanotubes (MWCNT) in Interpreting Infrared and Raman Spectra of Human Cancer Cells, Tissues and Tumors. Oncogen 2(2): 7. 
175. A Heidari (2018) A Clinical and Molecular Pathology Investigation of Correlation Spectroscopy (COSY), Exclusive Correlation Spectroscopy (ECOSY), Total Correlation Spectroscopy (TOCSY), Heteronuclear Single-Quantum Correlation Spectroscopy (HSQC) and Heteronuclear Multiple-Bond Correlation Spectroscopy (HMBC) Comparative Study on Malignant and Benign Human Cancer Cells, Tissues and Tumors under Synchrotron and Synchrocyclotron Radiations Using Cyclotron versus Synchrotron, Synchrocyclotron and the Large Hadron Collider (LHC) for Delivery of Proton and Helium Ion (Charged Particle) Beams for Oncology Radiotherapy. European Journal of Advances in Engineering and Technology 5(7): 414-426

176.A Heidari (2018) Nano Molecules Incorporation into the Nano Polymeric Matrix (NPM) by Immersion of the Nano Polymeric Modified Electrode (NPME) as Molecular Enzymes and Drug Targets for Human Cancer Cells, Tissues and Tumors Treatment under Synchrotron and Synchrocyclotron Radiations. J Oncol Res 1(1): 1-20

177.A Heidari (2018) Use of Molecular Enzymes in the Treatment of Chronic Disorders. Canc Oncol Open Access J 1(1): $12-15$

178. A Heidari, Vibrational Biospectroscopic Study and Chemical Structure Analysis of Unsaturated Polyamides Nanoparticles as Anti-Cancer Polymeric Nanomedicines Using Synchrotron Radiation. International Journal of Advanced Chemistry 6(2): 167-189

179. A Heidari (2018) Adamantane, Irene, Naftazone and Pyridine-Enhanced Precatalyst Preparation Stabilization and Initiation (PEPPSI) Nano Molecules. Madridge J Nov Drug Res 2(1): 61-67

180.A Heidari (2018) Heteronuclear Single-Quantum Correlation Spectroscopy (HSQC) and Heteronuclear Multiple-Bond Correlation Spectroscopy (HMBC) Comparative Study on Malignant and Benign Human Cancer Cells and Tissues with the Passage of Time under Synchrotron Radiation. Madridge J Nov Drug Res 2(1): 68-74

181. A Heidari, R Gobato (2018) A Novel Approach to Reduce Toxicities and to Improve Bioavailabilities of DNA/ RNA of Human Cancer Cells-Containing Cocaine (Coke), Lysergide (Lysergic Acid Diethyl Amide or LSD), $\Delta^{9}-$ Tetrahydrocannabinol (THC) [(-)-trans- $\Delta^{9}$-Tetrahydrocannabinol], Theobromine (Xantheose), Caffeine, Aspartame
(APM) (NutraSweet) and Zidovudine (ZDV) [Azidothymidine (AZT)] as Anti-Cancer Nano Drugs by Coassembly of Dual Anti-Cancer Nano Drugs to Inhibit DNA/RNA of Human Cancer Cells Drug Resistance. Parana Journal of Science and Education 4(6): 1-17

182.A Heidari, R Gobato (2018) Ultraviolet Photoelectron Spectroscopy (UPS) and Ultraviolet-Visible (UV-Vis) Spectroscopy Comparative Study on Malignant and Benign Human Cancer Cells and Tissues with the Passage of Time under Synchrotron Radiation. Parana Journal of Science and Education 4(6): 18-33

183. R Gobato, A Heidari, A Mitra (2018) The Creation of C13H20BeLi2SeSi. The Proposal of a Bio-Inorganic Molecule, Using Ab Initio Methods for the Genesis of a Nano Membrane. Arc Org Inorg Chem Sci 3(4). AOICS.MS.ID.000167

184.R Gobato, A Heidari, A Mitra (2018) Using the Quantum Chemistry for Genesis of a Nano Biomembrane with a Combination of the Elements $\mathrm{Be}, \mathrm{Li}, \mathrm{Se}, \mathrm{Si}, \mathrm{C}$ and $\mathrm{H}, \mathrm{Re}-$ searchGate, See discussions, stats, and author profiles for this publication at: https://www.researchgate.net/publication/326201181

185.R Gobato, A Heidari (2018) Using the Quantum Chemistry for Genesis of a Nano Biomembrane with a Combination of the Elements Be, Li, Se, Si, C and H. J Nanomed Res.7(4): 241凶252

186. A Heidari (2018) Bastadins and Bastaranes-Enhanced Precatalyst Preparation Stabilization and Initiation (EPPSI) Nano Molecules. Glob Imaging Insights 3(4): 1-7

187.A Heidari (2018) Fucitol, Pterodactyladiene, DEAD or DEADCAT (DiEthyl AzoDiCArboxylaTe), Skatole, the NanoPutians, Thebacon, Pikachurin, Tie Fighter, Spermidine and Mirasorvone Nano Molecules Incorporation into the Nano Polymeric Matrix (NPM) by Immersion of the Nano Polymeric Modified Electrode (NPME) as Molecular Enzymes and Drug Targets for Human Cancer Cells, Tissues and Tumors Treatment under Synchrotron and Synchrocyclotron Radiations. Glob Imaging Insights 3(4): 1-8

188.E Dadvar, A Heidari (2018) A Review on Separation Techniques of Graphene Oxide (GO)/Base on Hybrid Polymer Membranes for Eradication of Dyes and Oil Compounds: Recent Progress in Graphene Oxide (GO)/Base on Polymer Membranes-Related Nanotechnologies. Clin Med Rev Case Rep 5: 228

Citation: Heidari A (2019). The Importance of Attenuated Total Reflectance Fourier Transform Infrared (ATR-FTIR) and Raman Biospectroscopy of Single-Walled Carbon Nanotubes (SWCNT) and Multi-Walled Carbon Nanotubes (MWCNT) in Interpreting Infrared and Raman Spectra of Human Cancer Cells, Tissues and Tumors. Oncogen 2(2): 7. 
189. A Heidari, R Gobato (2018) First-Time Simulation of Deoxyuridine Monophosphate (dUMP) (Deoxyuridylic Acid or Deoxyuridylate) and Vomitoxin (Deoxynivalenol (DON)) ((3a,7a)-3,7,15-Trihydroxy-12,13-Epoxytrichothec-9-En-8-One)-Enhanced Precatalyst Preparation Stabilization and Initiation (EPPSI) Nano Molecules Incorporation into the Nano Polymeric Matrix (NPM) by Immersion of the Nano Polymeric Modified Electrode (NPME) as Molecular Enzymes and Drug Targets for Human Cancer Cells, Tissues and Tumors Treatment under Synchrotron and Synchrocyclotron Radiations. Parana Journal of Science and Education 4(6): 46-67

190.A Heidari (2018) Buckminsterfullerene (Fullerene), Bullvalene, Dickite and Josiphos Ligands Nano Molecules Incorporation into the Nano Polymeric Matrix (NPM) by Immersion of the Nano Polymeric Modified Electrode (NPME) as Molecular Enzymes and Drug Targets for Human Hematology and Thromboembolic Diseases Prevention, Diagnosis and Treatment under Synchrotron and Synchrocyclotron Radiations. Glob Imaging Insights 3(4): $1-7$

191.A Heidari (2018) Fluctuation X-Ray Scattering (FXS) and Wide-Angle X-Ray Scattering (WAXS) Comparative Study on Malignant and Benign Human Cancer Cells and Tissues under Synchrotron Radiation, Glob Imaging Insights 3(4): $1-7$

192. A Heidari (2018) A Novel Approach to Correlation Spectroscopy (COSY), Exclusive Correlation Spectroscopy (ECOSY), Total Correlation Spectroscopy (TOCSY), Incredible Natural-Abundance Double-Quantum Transfer Experiment (INADEQUATE), Heteronuclear Single-Quantum Correlation Spectroscopy (HSQC), Heteronuclear Multiple-Bond Correlation Spectroscopy (HMBC), Nuclear Overhauser Effect Spectroscopy (NOESY) and Rotating Frame Nuclear Overhauser Effect Spectroscopy (ROESY) Comparative Study on Malignant and Benign Human Cancer Cells and Tissues under Synchrotron Radiation. Glob Imaging Insights 3(5): 1-9

193.A Heidari (2018) Terphenyl-Based Reversible Receptor with Rhodamine, Rhodamine-Based Molecular Probe, Rhodamine-Based Using the Spirolactam Ring Opening, Rhodamine B with Ferrocene Substituent, Calix[4]AreneBased Receptor, Thioether + Aniline-Derived Ligand Framework Linked to a Fluorescein Platform, Mercuryflu- or-1 (Flourescent Probe), N,N'-Dibenzyl-1,4,10,13-Tetraraoxa-7,16-Diazacyclooctadecane and TerphenylBased Reversible Receptor with Pyrene and Quinoline as the Fluorophores-Enhanced Precatalyst Preparation Stabilization and Initiation (EPPSI) Nano Molecules. Glob Imaging Insights 3(5): 1-9

194.A Heidari (2018) Small-Angle X-Ray Scattering (SAXS), Ultra-Small Angle X-Ray Scattering (USAXS), Fluctuation X-Ray Scattering (FXS), Wide-Angle X-Ray Scattering (WAXS), Grazing-Incidence Small-Angle X-Ray Scattering (GISAXS), Grazing-Incidence Wide-Angle X-Ray Scattering (GIWAXS), Small-Angle Neutron Scattering (SANS), Grazing-Incidence Small-Angle Neutron Scattering (GISANS), X-Ray Diffraction (XRD), Powder X-Ray Diffraction (PXRD), Wide-Angle X-Ray Diffraction (WAXD), Grazing-Incidence X-Ray Diffraction (GIXD) and EnergyDispersive X-Ray Diffraction (EDXRD) Comparative Study on Malignant and Benign Human Cancer Cells and Tissues under Synchrotron Radiation. Glob Imaging Insights 3(5): $1-10$

195.A Heidari (2018) Nuclear Resonant Inelastic X-Ray Scattering Spectroscopy (NRIXSS) and Nuclear Resonance Vibrational Spectroscopy (NRVS) Comparative Study on Malignant and Benign Human Cancer Cells and Tissues under Synchrotron Radiation. Glob Imaging Insights 3(5): 1-7

196.A Heidari (2018) Small-Angle X-Ray Scattering (SAXS) and Ultra-Small Angle X-Ray Scattering (USAXS) Comparative Study on Malignant and Benign Human Cancer Cells and Tissues under Synchrotron Radiation. Glob Imaging Insights 3(5): 1-7

197. A Heidari (2018) Curious Chloride $(\mathrm{CmCl} 3)$ and Titanic Chloride (TiCl4)-Enhanced Precatalyst Preparation Stabilization and Initiation (EPPSI) Nano Molecules for Cancer Treatment and Cellular Therapeutics. J. Cancer Research and Therapeutic Interventions 1(1): 1-10

198. R Gobato, M R R Gobato, A Heidari, A Mitra (2018) Spectroscopy and Dipole Moment of the Molecule $\mathrm{C} 13 \mathrm{H} 20 \mathrm{Be}-$ Li2SeSi via Quantum Chemistry Using Ab Initio, HartreeFock Method in the Base Set CC-pVTZ and 6-311G**(3df, 3pd). Arc Org Inorg Chem Sci 3(5): 402-409

199. A Heidari, C60 and C70-Encapsulating Carbon Nanotubes Incorporation into the Nano Polymeric Matrix (NPM) by Immersion of the Nano Polymeric Modified Electrode 
(NPME) as Molecular Enzymes and Drug Targets for Human Cancer Cells, Tissues and Tumors Treatment under Synchrotron and Synchrocyclotron Radiations. Integr Mol Med, 5(3): 1-8

200.A Heidari (2018) Two-Dimensional (2D) $1 \mathrm{H}$ or Proton NMR, 13C NMR, 15N NMR and 31P NMR Spectroscopy Comparative Study on Malignant and Benign Human Cancer Cells and Tissues under Synchrotron Radiation with the Passage of Time. Glob Imaging Insights 3(6): 1-8

201.A Heidari (2018) FT-Raman Spectroscopy, Coherent AntiStokes Raman Spectroscopy (CARS) and Raman Optical Activity Spectroscopy (ROAS) Comparative Study on Malignant and Benign Human Cancer Cells and Tissues with the Passage of Time under Synchrotron Radiation. Glob Imaging Insights 3(6): 1-8

202. A Heidari (2018) A Modern and Comprehensive Investigation of Inelastic Electron Tunneling Spectroscopy (IETS) and Scanning Tunneling Spectroscopy on Malignant and Benign Human Cancer Cells, Tissues and Tumors through Optimizing Synchrotron Microbeam Radiotherapy for Human Cancer Treatments and Diagnostics: An Experimental Biospectroscopic Comparative Study. Glob Imaging Insights 3(6): 1-8

203. A Heidari (2018) A Hypertension Approach to Thermal Infrared Spectroscopy and Photothermal Infrared Spectroscopy Comparative Study on Malignant and Benign Human Cancer Cells and Tissues under Synchrotron Radiation with the Passage of Time. Glob Imaging Insights 3(6): 1-8

204.A Heidari (2018) Incredible Natural-Abundance DoubleQuantum Transfer Experiment (INADEQUATE), Nuclear Overhauser Effect Spectroscopy (NOESY) and Rotating Frame Nuclear Overhauser Effect Spectroscopy (ROESY) Comparative Study on Malignant and Benign Human Cancer Cells and Tissues under Synchrotron Radiation. Glob Imaging Insights 3(6): 1-8

205.A Heidari (2018) 2-Amino-9-((1S, 3R, 4R)-4-Hydroxy-3-(Hydroxymethyl)-2-Methylenecyclopentyl)-1H-Purin-6(9H)-One, 2-Amino-9-((1R, 3R, 4R)-4-Hydroxy-3-(Hydroxymethyl)-2-Methylenecyclopentyl)-1H-Purin-6(9H)-One, 2-Amino-9-((1R, 3R, 4S)-4-Hydroxy-3-(Hydroxymethyl)-2-Methylenecyclopentyl)-1H-Purin-6(9H)-One and 2-Amino-9-((1S, 3R
4S)-4-Hydroxy-3-(Hydroxymethyl)-2-Methylenecyclopentyl)-1H-Purin-6(9H)-One-Enhanced Precatalyst Preparation Stabilization and Initiation Nano Molecules. Glob Imaging Insights 3(6): 1-9

206.R Gobato, M R R Gobato, A Heidari, A Mitra, Spectroscopy and Dipole Moment of the Molecule C13H20BeLi2SeSi via Quantum Chemistry Using Ab Initio, Hartree-Fock Method in the Base Set CC-pVTZ and 6-311G**(3df, 3pd), American Journal of Quantum Chemistry and Molecular Spectroscopy 2(1): 9-17

207.A Heidari (2018) Production of Electrochemiluminescence (ECL) Biosensor Using Os-Pd/HfC Nanocomposites for Detecting and Tracking of Human Gastroenterological Cancer Cells, Tissues and Tumors. Int J Med Nano Res 5: $1,22-34$

208. A Heidari (2018) Enhancing the Raman Scattering for Diagnosis and Treatment of Human Cancer Cells, Tissues and Tumors Using Cadmium Oxide (CdO) Nanoparticles. J Toxicol Risk Assess 4: 1, 12-25

209.A Heidari (2018) Human Malignant and Benign Human Cancer Cells and Tissues Biospectroscopic Analysis under Synchrotron Radiation Using Anti-Cancer Nano Drugs Delivery. Integr Mol Med 5(5): 1-13

210. A Heidari (2018) Analogous Nano Compounds of the Form $\mathrm{M}(\mathrm{C} 8 \mathrm{H} 8) 2$ Exist for $\mathrm{M}=(\mathrm{Nd}, \mathrm{Tb}, \mathrm{Pu}, \mathrm{Pa}, \mathrm{Np}, \mathrm{Th}$, and Yb)-Enhanced Precatalyst Preparation Stabilization and Initiation (EPPSI) Nano Molecules. Integr Mol Med 5(5): $1-8$

211. A Heidari (2018) Hadron Spectroscopy, Baryon Spectroscopy and Meson Spectroscopy Comparative Study on Malignant and Benign Human Cancer Cells and Tissues under Synchrotron Radiation. Integr Mol Med 5(5): 1-8

212.R Gobato, M R R Gobato, A Heidari (2019) Raman Spectroscopy Study of the Nano Molecule C13H20BeLi2SeSi Using ab initio and Hartree-Fock Methods in the Basis Set CC-pVTZ and 6-311G** (3df, 3pd). International Journal of Advanced Engineering and Science 7(1): 14-35

213. A Heidari, R Gobato (2019) Evaluating the Effect of AntiCancer Nano Drugs Dosage and Reduced Leukemia and Polycythemia Vera Levels on Trend of the Human Blood and Bone Marrow Cancers under Synchrotron Radiation. Trends in Res 2(1): 1-8 
214. A Heidari, R Gobato, Assessing the Variety of Synchrotron, Synchrocyclotron and LASER Radiations and Their Roles and Applications in Human Cancer Cells, Tissues and Tumors Diagnosis and Treatment. Trends in Res. 2(1): 1-8

215. A Heidari, R Gobato (2019) Pros and Cons Controversy on Malignant Human Cancer Cells, Tissues and Tumors Transformation Process to Benign Human Cancer Cells, Tissues and Tumors. Trends in Res 2(1): 1-8

216. A Heidari, R Gobato (2019) Three-Dimensional (3D) Simulations of Human Cancer Cells, Tissues and Tumors for Using in Human Cancer Cells, Tissues and Tumors Diagnosis and Treatment as a Powerful Tool in Human Cancer Cells, Tissues and Tumors Research and Anti-Cancer Nano Drugs Sensitivity and Delivery Area Discovery and Evaluation. Trends in Res 2(1): 1-8

217.A Heidari, R Gobato (2019) Investigation of Energy Production by Synchrotron, Synchrocyclotron and LASER Radiations in Human Cancer Cells, Tissues and Tumors and Evaluation of Their Effective on Human Cancer Cells, Tissues and Tumors Treatment Trend. Trends in Res 2(1): 1-8

218. A Heidari, R Gobato (2019) High-Resolution Mapping of DNA/RNA Hypermethylation and Hypomethylation Process in Human Cancer Cells, Tissues and Tumors under Synchrotron Radiation. Trends in Res 2(2): 1-9

219. A Heidari (2019) A Novel and Comprehensive Study on Manufacturing and Fabrication Nanoparticles Methods and Techniques for Processing Cadmium Oxide (CdO) Nanoparticles Colloidal Solution. Glob Imaging Insights 4(1): $1-8$
220. A Heidari (2019) A Combined Experimental and Computational Study on the Catalytic Effect of Aluminum Nitride Nanocrystal (AIN) on the Polymerization of Benzene, Naphthalene, Anthracene, Phenanthrene, Chrysene and Tetracene. Glob Imaging Insights 4(1): 1-8

221. A Heidari (2019) Novel Experimental and Three-Dimensional (3D) Multiphysics Computational Framework of Michaelis-Menten Kinetics for Catalyst Processes Innovation, Characterization and Carrier Applications. Glob Imaging Insights 4(1): 1-8

222.A Heidari (2019) The Hydrolysis Constants of Copper (I) (CU+) and Copper (II) (Cu2+) in Aqueous Solution as a Function of $\mathrm{pH}$ Using a Combination of $\mathrm{pH}$ Measurement and Biospectroscopic Methods and Techniques. Glob Imaging Insights 4(1): 1-8

223.A Heidari (2019) Vibrational Biospectroscopic Study of Ginormous Virus-Sized Macromolecule and Polypeptide Macromolecule as Mega Macromolecules Using Attenuated Total Reflectance-Fourier Transform Infrared (ATRFTIR) Spectroscopy and Mathematica 11.3. Glob Imaging Insights 4(1): 1-8

224. A Heidari (2019) Three-Dimensional (3D) Imaging Spectroscopy of Carcinoma, Sarcoma, Leukemia, Lymphoma, Multiple Myeloma, Melanoma, Brain and Spinal Cord Tumors, Germ Cell Tumors, Neuroendocrine Tumors and Carcinoid Tumors under Synchrotron Radiation. Glob Imaging Insights 4(1): 1-9

Copyright: $\odot 2019$ Heidari A. This is an open-access article distributed under the terms of the Creative Commons Attribution License, which permits unrestricted use, distribution and reproduction in any medium, provided the original author and source are credited.

Citation: Heidari A (2019). The Importance of Attenuated Total Reflectance Fourier Transform Infrared (ATR-FTIR) and Raman Biospectroscopy of Single-Walled Carbon Nanotubes (SWCNT) and Multi-Walled Carbon Nanotubes (MWCNT) in Interpreting Infrared and Raman Spectra of Human Cancer Cells, Tissues and Tumors. Oncogen 2(2): 7. 